\title{
Volcanically-Induced Transient Atmospheres on the Moon: Assessment of Duration, Significance and Contributions to Polar Volatile Traps
}

11 James W. Head ${ }^{1}$, Lionel Wilson ${ }^{1,2}$, Ariel N. Deutsch ${ }^{1}$, Malcolm J. Rutherford ${ }^{\mathbf{1}}$, and 12 Alberto E. Saal ${ }^{1}$

$13{ }^{1}$ Department of Earth, Environmental and Planetary Sciences, Brown University, 14 Providence, RI 02912 USA.

$15{ }^{2}$ Lancaster Environment Centre, Lancaster University, Lancaster LA1 4YQ UK.

17 Corresponding author: James Head (james_head@brown.edu)

19 Key Points:

- A transient lunar atmosphere from peak volcanic degassing lasting up to 70 Ma was recently proposed as a source of lunar polar volatiles.

- We forward-model individual eruption volume, degassing patterns, and duration of periods between eruptions (repose periods), finding that:

- Transient, volcanically-induced atmospheres are inefficient sources for volatile delivery to permanently shadowed lunar polar regions. 


\section{Abstract}

A transient lunar atmosphere formed during a peak period of volcanic outgassing and lasting up to about $\sim 70 \mathrm{Ma}$ was recently proposed. We utilize forward-modeling of individual lunar basaltic eruptions and the observed geologic record to predict eruption frequency, magma volumes, and rates of volcanic volatile release. Typical lunar mare basalt eruptions have volumes of $\sim 10^{2}-10^{3} \mathrm{~km}^{3}$, last less than a year, and have a rapidly decreasing volatile release rate. The total volume of lunar mare basalts erupted is small and the repose period between individual eruptions is predicted to range from 20,000 60,000 years. Only under very exceptional circumstances could sufficient volatiles be released in a single eruption to create a transient atmosphere with a pressure as large as $\sim 0.5 \mathrm{~Pa}$. The frequency of eruptions was likely too low to sustain any such atmosphere for more than a few thousand years. Transient, volcanically-induced atmospheres were probably inefficient sources for volatile delivery to permanently shadowed lunar polar regions.

\section{Plain Language Summary}

43 Could gas emitted from volcanic eruptions during the most intense and voluminous period of lunar mare volcanism produce a temporary lunar atmosphere? Could the presence of such an atmosphere enable volatiles to reach the cold traps in the permanently shadowed regions at the lunar poles? We use information from lunar geology and sample analyses to predict the number of eruptions with time, the volume of individual eruptions, the rates of volcanic gas release during each eruption, and the time between eruptions. We find that only under rare circumstances could a single eruption or two eruptions closely-spaced in time release enough gas to create a transient atmosphere with a pressure as large as $\sim 0.5 \mathrm{~Pa}$. Furthermore, it is difficult to sustain such an atmosphere for more than a few thousand years. These results suggest that volcanicallyproduced atmospheres are inefficient source mechanisms for delivery of volatiles to form deposits in permanently shadowed polar regions of the Moon; this favors volatile-rich impactors as the major source of polar ice.

\section{Introduction}

The current atmosphere of the Moon is a stable, low-density surface boundary exosphere ( 10 $0^{-12}$ mbar) (Stern, 1999; Cook et al., 2013; Benna et al., 2015) and is thought to have changed little in the last several billion years. Volcanism, a significant source of volatile supply to planetary atmospheres throughout planetary history, is known to have been much more important in early lunar history (mare basalt volcanism; Shearer et al., 2008; Head and Wilson, 2017), spanning from over 4 billion years ago (beginning with cryptomaria; Whitten et al., 2015a,b), reaching peak fluxes between 3 and $4 \mathrm{Ga}$, and declining to much lower levels between 3 and $1 \mathrm{Ga}$ (Hiesinger et al., 2011; Pasckert et

66 al., 2015; Head et al., 2020).

Needham and Kring (2017) assessed lunar mare basalt volcanic flux estimates and volatile release abundances to address whether these patterns might lead to a transient or sustained lunar atmosphere early in lunar history. Using the distribution and quantity of mare basalt fill, and estimates of its age, they calculated the magma flux (the volume of 
rate of volatiles on the basis of estimates derived from the analysis of lunar samples (e.g., Saal et al., 2008; Rutherford and Papale, 2009; Hauri et al., 2011; Kring, 2014). Using estimates of mare basalt unit ages (e.g., Hiesinger et al, 2011) and thicknesses (Weider et al., 2010), Needham and Kring (2017) concluded that during a period of peak mare emplacement and volcanic volatile release at $\sim 3.5 \mathrm{Ga}$ (Figs. S1a,b), the maximum atmospheric pressure at the lunar surface could have reached $\sim 1 \mathrm{kPa}(\sim 1.5$ times greater than the current atmospheric surface pressure of Mars) (Fig. S1c) and that this lunar atmosphere could have persisted for $\sim 70$ million years before fully dissipating (Fig. S1c). They further pointed out that even though most of the volcanically-released volatiles will have been lost to space, if only $0.1 \%$ of the water released during these eruptions migrated to the permanently shadowed polar regions of the Moon, then the resulting hydrogen mass could account for the entire currently observed hydrogen deposits located there (Eke et al., 2009; Livengood et al., 2018).

We adopt a different approach, using improved models of the generation, ascent and eruption of lunar basaltic magma (Wilson and Head, 2017), to predict flow volumes, eruption frequencies (Head and Wilson, 2017), and temporal magmatic volatile release patterns in individual eruptions (Rutherford et al., 2017; Wilson and Head, 2018). Key components of this analysis are 1) the range (and mean value) of magma volumes erupted in individual eruptions, 2) the masses, and hence volumes, of the various gases released in any one eruption, 3 ) the duration of the eruption and the gas release rate (varying significantly as the eruption progresses), 4) the typical time intervals between eruptions (repose periods) as a function of geologic time and 5) the timescale for the dissipation of an atmosphere once one is emplaced. We review the geological basis for the first four components, examine the potential time-dependence and variability of gas release in an individual typical eruption, and finally address the question: Are these gas-release values sufficient to form a transient atmosphere and, if so, for what duration? We then compare our findings with the broad-scale, time-averaged peak flux estimates of Needham and Kring (2017) (see the Supporting Material), and address similarities and differences and their causes, and how estimates might be refined in the future. We conclude by assessing whether the forward-modeling predictions of gas-release rates are sufficient to: 1) act as a significant supply of volatiles to the permanently shadowed lunar polar cold-trap regions and 2) form a transient lunar atmosphere for a period sufficient to favor astrobiological activity as suggested by Schulze-Makuch and Crawford (2018).

\section{Forward Modeling Lunar Mare Basaltic Eruptions}

Wilson and Head (2017) and Head and Wilson (2017) improved earlier theoretical models for the generation, ascent and eruption of basaltic magma on the Moon (Wilson and Head, 1981; Head and Wilson, 1992) by using new data on crustal thickness and density (Wieczorek et al., 2013), magma volatile inventories (Rutherford et al., 2017), and surface morphology, topography and structure (from Lunar Reconnaissance Orbiter). They showed that ongoing partial melting in buoyant diapirs deep in the mantle overpressurizes the source regions, producing sufficient stress to cause brittle fracturing; a magma-filled crack grows, disconnects from its source and propagates to the surface as a blade-shaped, convex-upward dike. The typical turbulent magma rise speeds that result are $\sim 10$ to a few tens of $\mathrm{m} \mathrm{s}^{-1}$, dike widths are $\sim 100 \mathrm{~m}$, and eruption rates from 1-10 km long fissure vents are $\sim 10^{5}$ to $10^{6} \mathrm{~m}^{3} \mathrm{~s}^{-1}$. Lunar eruption volume fluxes derived from lava 
118 sinuous rille lengths and depths or flow thicknesses and surface slopes are $\sim 10^{5}$ to $10^{6} \mathrm{~m}^{3}$

$119 \mathrm{~s}^{-1}$ (volume-limited lava flows) and $>10^{4}$ to $10^{5} \mathrm{~m}^{3} \mathrm{~s}^{-1}$ (rilles). The volume of magma

120 released in one event is predicted to be in the range $10^{2}-10^{3} \mathrm{~km}^{3}$ (Wilson and Head, 2017;

121 Head and Wilson, 2017). Thus, if all the magma were extruded from these dike events

122 and spread evenly across the surface in $25 \mathrm{~m}$ thick flows, they would occupy areas of

1234000 to $40,000 \mathrm{~km}^{2}$, well within the range of thicknesses and areas of mapped and dated

124 (e.g., Hiesinger et al., 2011) lunar mare lava flows. We now summarize aspects of these

125

126

127

128

129

130

131

132

133

134

135

136

137

138

139

140

141

142

143

144

145

146

147

148

149

150

151

152

153

154

155

156

157

158

159

160

161

162

163

2.1) Individual mare basalt eruption volumes: Range and typical values: Individual eruption volumes of typical visible, and therefore most recent, lava flow deposits, are at least $\sim 200-300 \mathrm{~km}^{3}$ (Head and Wilson, 2017) (Table 1a). In addition, Head and Wilson (1981) estimated the minimum volume of lava, $100 \mathrm{~km}^{3}$, needed to thermo-mechanically erode the preserved sinuous rille channels. Applying the same method to the largest lunar rille, Schroeter's Valley, implies a volume of $2000 \mathrm{~km}^{3}$ and a duration of $\sim 150$ days. On the basis of these predictions and observations, we adopt a range of individual eruption volumes, $V$, of $100-2000 \mathrm{~km}^{3}$ (Table 1a), with typical values in the range $100-300 \mathrm{~km}^{3}$.

2.2) Total mare basalt erupted volumes: Using mare basin lava fill depth estimates, the total volume, $V_{\mathrm{t}}$, of all volcanic products erupted on the Moon over its lifetime is $\sim 10^{7} \mathrm{~km}^{3}$ (Head and Wilson, 1992; Evans et al., 2016). The absolute dates of specific eruptions are unknown, but crater size-frequency distribution-derived dates of units mapped from orbit, and stratigraphic relationships, imply that the overall time span of the vast majority of lunar volcanic activity was $\sim 2 \mathrm{Ga}$ (Hiesinger et al., 2011; Head and Wilson, 2017; Head et al., 2020).

2.3) Number of eruptions, average eruption rates, and estimated repose periods: Using the $100-300 \mathrm{~km}^{3}$ average eruption volume, the $\sim 10^{7} \mathrm{~km}^{3}$ total erupted volume of mare basalts, and the $\sim 2$ Ga duration of volcanism, we calculate a total of $\sim 30,000$ to 100,000 eruptions with an average repose period of 20,000 to 60,000 years. These repose times assume that eruptions occur randomly in space and time, in which case two eruptions might occur with a much smaller time interval; however, we show in the Supplementary Material that eruptions at intervals close enough in time to influence our conclusions will be rare. Accounting for lunar thermal evolution (conductive cooling and lithospheric thickening) in terms of mare mantle production rates and the evolving lithospheric stress state and magnitude (Head and Wilson, 2017), we would predict decreasing volumes of magma with time. If three times as much magma was erupted in the 4-3 Ga period than in the 3-2 Ga period, for example, the earlier eruptions would have occurred every 13,000 to 40,000 years.

2.4) Eruption durations: Analyses of the dynamics of lunar eruptions allow us to estimate the volume fluxes, $F_{1}$, of lava forming surface flows and sinuous rilles (Wilson and Head 2017; Head and Wilson, 2017); coupled with the typical erupted volumes described above, these give values for the typical durations, $\tau_{\mathrm{e}}$, of these eruptions (Table 1a), all less than 6 months, with most eruption durations in the 1-3 month range.

2.5) Magmatic volatiles and volatile release patterns: Analyses of lavas and pyroclastics sampled by the Apollo missions (Saal et al., 2008; Rutherford and Papale, 2009; Hauri et al., 2011; Chen et al., 2015; Rutherford et al., 2017; Renggli et al., 2017; $\mathrm{Ni}$ et al., 2019) provide estimates for the compositions and amounts of released volatiles. 
164 The highest amount is that for picritic magmas, $3400 \mathrm{ppm}$ (Rutherford et al., 2017). At 165 the other extreme, Head and Wilson (2017) found that the radii of the lava ponds feeding 166 the lava flows eroding sinuous rille channels imply total magma volatile contents of no more than $700 \mathrm{ppm}$. We adopt $2000 \mathrm{ppm}$, close to the average of these extremes. The Rutherford et al. (2017) volatiles are $\mathrm{CO}, \mathrm{H}_{2} \mathrm{O}, \mathrm{SO}_{2}, \mathrm{H}_{2} \mathrm{~S}, \mathrm{COS}$ and $\mathrm{F}$ present in amounts $n_{\mathrm{i}}$ of $1395,1133,327,168,327$ and $50 \mathrm{ppm}$, respectively, and with molecular masses $m_{\mathrm{i}}$ of 28.0, 18.0, 64.1, 34.1,60.1 and 19.0, respectively, the mean molecular weight is $\Sigma\left(n_{\mathrm{i}}\right.$ $\left.m_{\mathrm{i}}\right) / \sum n_{\mathrm{i}}=31.4 \mathrm{~kg} \mathrm{kmol}^{-1}$. The corresponding values for alternative compositions suggested by Renggli et al. (2017) and Newcombe et al. (2017) are 48.9 and $22.2 \mathrm{~kg}$ $\mathrm{kmol}^{-1}$, respectively; we adopt the Rutherford et al. (2017) value as typical for subsequent calculations.

2.6) Volatile input to the atmosphere: We first calculate the total volume of gas released from an eruption of a specific volume, and then analyze the time-history of gas release in the several phases of an individual eruption (Rutherford et al., 2017; Wilson and Head, 2018). Multiplying the dense-rock-equivalent erupted volume $V$ by the typical density of lunar basaltic magma, $\rho_{\mathrm{m}}=\sim 3000 \mathrm{~kg} \mathrm{~m}^{-3}$, yields the magma mass erupted, and multiplying that by the total released gas mass fraction $n_{\mathrm{t}}=\sum n_{\mathrm{i}}$ gives the total gas mass released, $M_{\mathrm{g}}$. Finally dividing $M_{\mathrm{g}}$ by $\tau_{\mathrm{e}}$ yields the average gas mass input rate to the atmosphere, $F_{\mathrm{g}}$. Table 1a summarizes these values. However, gas release during an eruption is non-linear, and typically declines with time (Wallace et al., 2015). Speciation, relative abundances and fluxes of specific volatiles can vary during a single eruption. Could such variations in individual volcanic eruptions result in spikes in volatile output contributing to an atmosphere that might be underestimated by deriving an average value for the entire eruption? We now employ an updated version of a recent model of the typical phases of a lunar eruption to assess these questions.

Wilson and Head (2018), using data from Rutherford et al. (2017), assessed mare basalt gas release patterns during individual volcanic eruptions as a basis for predicting the effect of sequential gas production, bubble nucleation and growth, magma and gas rise rates, bubble coalescence, and magma disruption processes. Subdividing typical lunar eruptions into four phases (Fig. 1a), they showed how these phases of mare basalt eruption, together with total dike volumes, initial magma volatile content, vent configuration, and magma discharge rate, could assist in relating the wide range of seemingly disparate volcanic features to a common set of eruption processes. Figure 1 updates the values given by Wilson and Head (2018) using a more detailed integration of the eruption rate model based on work in progress.

In Phase 1, which is very short-lived, the rising dike penetrates to the surface, and initiates the transient gas release phase. This very explosive phase is due to concentration of volatiles into a low-pressure area near the upper propagating dike tip (Wilson \& Head, 2003). Pure gas may extend 100-200 m down from the top of the dike, above a high vesicularity foam layer extending downward $\sim 10 \mathrm{~km}$. Eruption of this gasrich magma dike tip takes as little as a few minutes, resulting in an extremely thin but very widespread deposit, consistent with volcanic glass beads ubiquitous in lunar soils.

During Phase 2, the high-flux hawaiian eruptive phase, the dike continues to rise toward a neutral buoyancy configuration. This phase is characterized by the highest magma discharge rate during the eruption, $\sim 10^{6} \mathrm{~m}^{3} / \mathrm{s}$, involving a near-steady explosive magma eruption; the volatile content is representative of the bulk of the magma. This 
210 phase is characterized by formation of a relatively steady hawaiian fire fountain, largely

211 optically dense. Submillimeter-sized pyroclastic droplets lose gas efficiently and

212 accumulate with negligible cooling within a few to $10 \mathrm{~km}$ of the fissure, forming a lava

213 lake deficient in gas bubbles. For a short-lived eruption, lava that is largely degassed

214 flows away from the lake, initially turbulently, to form the distal part of the final lava

215 flow deposit. For a sufficiently long-lasting eruption, the lava will feed a flow eroding a

216 sinuous rille. More than $80 \%$ of the total dike magma volume would have been erupted

217 during this phase; the erupted magma volume flux decreases from $\sim 10^{6}$ to $\sim 10^{5} \mathrm{~m}^{3} \mathrm{~s}^{-1}$

218 over its typical 2-3 day duration.

219

220

221

222

223

224

225

226

227

228

229

230

231

232

233

234

235

236

237

238

239

240

241

242

243

244

245

246

247

248

249

250

251

252

253

254

255

Phase 3, the lower flux hawaiian to strombolian transition phase begins when the positive buoyancy of the lower part of the dike in the mantle balances the negative buoyancy of the upper part in the crust, and the eruption-feeding dike approaches an equilibrium. The lower dike tip stops rising, and fixing the vertical extent of the dike. The main driving process in this phase becomes the horizontal reduction in dike thickness due to: 1) decrease in internal excess pressure, and 2) relaxation of forced host rock deformation due to initial dike intrusion (Wilson \& Head, 2017). Shallow crust host rock deformation is probably elastic and rapid; hotter mantle rock deformation (surrounding the lower part of the dike) is more likely to be visco-elastic or viscous; this results in a much longer closure timescale. Magma vertical rise speed in the dike decreases greatly (to less than $1 \mathrm{~m} / \mathrm{s}$ ) during this period; this implies that the magma volume flux leaving the vent decreases similarly to a few $\times 10^{4} \mathrm{~m}^{3} \mathrm{~s}^{-1}$ during $\sim 3-5$ days. Reduction in vertical magma flow speed means that nucleating gas bubbles throughout the dike vertical extent can now rise through the liquid at an appreciable rate. There is ample time for larger bubbles to overtake smaller bubbles (especially $\mathrm{CO}$ bubbles being produced at great depths). This leads to coalescence and even greater growth; this in turn leads to very large bubbles - gas slugs - filling almost all of the dike width and producing strombolian surface explosions (Parfitt \& Wilson, 1995). The transition from hawaiian activity (Phase 2) to strombolian (Phase 3 ) occurs rapidly.

Phase 4, the dike closing, strombolian vesicular flow phase, begins when the activity becomes entirely strombolian. Horizontal dike closure continues due to tectonic stresses and magma is extruded at a low flux. Magma from the deepest dike parts continues to be forced upward to lower pressure levels thus continuing to produce some $\mathrm{CO}$ at all depths; the result is very minor, but continuing strombolian explosive activity above the vent. For magma still emerging from the vent, a stable crust will form and flow away as lava.

Two different pathways might occur during Phase 4 activity. In low flux eruptions (Phase 4a), Phase 4 might begin following of eruption of most of the magma in the dike and the volume flux has decreased to a very low level (Fig. 1a). Wilson and Head (2017) predict that the result will be the emplacement of vesicular lava in the vicinity of the vent as a series of cooling-limited flows potentially building a small, low shield. Erupted magma consists of liquid which contains bubbles (a mixture of gases and volatile elements) (Gaillard \& Scaillet, 2014; Renggli et al., 2017; Saal et al., 2018). These are determined by the thermodynamic equilibrium between the products of interactions (mainly between $\mathrm{H}_{2} \mathrm{O}$ and sulfur species) released over the last $<500 \mathrm{~m}$ of magma flux. Such gas bubbles would nucleate with diameters of $\sim 10-20 \mu \mathrm{m}$ and grow to $\sim 20-30 \mu \mathrm{m}$ at the surface; they remain stable within the lava (surface tension forces impose a 
retaining pressure of $\sim 30 \mathrm{kPa}$; Wilson \& Head, 2017). Lavas exsolving $\sim 1,000 \mathrm{ppm}$ of such gases would leave the vent as lava foams with vesicularities $>90 \%$ by volume. The topmost bubbles would likely have exploded into the overlying vacuum; this should produce a layer of bubble wall shards, and gas escapes easily through this accumulating debris layer until welding of particles and accumulated debris weight inhibited further foam disintegration. If the underlying lava still contained dissolved volatiles, the unvesiculated layer could become important during further lava cooling and crystallization if volatile concentration into the remaining liquid resulted in second boiling and additional post-emplacement vesiculation. Volatile contributions to the atmosphere of these latter-stage processes would be minimal, however, as the rates of diffusive volatile loss from vesiculated cooling and cooled lavas are extremely low.

A second potential outcome is predicted to occur in dikes that are vertically more extensive (Phase $4 \mathrm{~b}$, high flux). If a large fraction of total dike magma remains available for extrusion as vesicular lava, this lava can readily intrude into the still-hot interiors of the previously emplaced nonvesicular flows and cause flow inflation. The shallow parts ( $<400 \mathrm{~m}$ depth) of a dike feeding such intruding/inflating flows would contain not yet exsolved water and sulfur compounds. The resulting inflated flows would cool on a timescale of weeks: volatile concentration into the residual liquid as crystallization occurred would then lead to second boiling. The new population of gas bubbles could cause a possibly extensive further inflation episode (Wilson et al., 2019). The resulting magmatic foam and gas could escape through cracks in the lava crust caused by inflation, but again the gas flux into the atmosphere would be minimal.

Eruption Phase 4 duration is controlled by the global stress state of the lithosphere (both its nature and magnitude), influencing host rocks visco-elastic relaxation, and by magma cooling in the dike. Lunar thermal history (Solomon \& Head, 1980) suggests extensional lithospheric stresses during the first $\sim 1 \mathrm{Ga}$, followed by compressive stresses at $\sim 3.6 \mathrm{Ga}$ as the interior cooled. This would encourage more closure of dikes in geologically more recent eruptions. Dike models (Wilson \& Head, 2017) predict that Phase 4 dikes had initial widths of at least 10-20 m. Cooling and solidification by conduction alone of near-stagnant magma in such dikes would occur 1-2 years after the end of an eruption.

In summary, the majority of the volume of magma erupted during a typical lunar eruption occurs in Phase 2 and 3 (Fig. 1a). The rise speed of magma during these phases is so large that gas bubbles stay locked to the magma, and so the vast majority of gas release into the atmosphere during a lunar eruption also occurs during Phases 2 and 3, phases that take place over about 5-10 days, less than about 25\% of the total eruption duration. We now turn to a discussion of the implications of the 1) total gas release patterns and 2) gas release patterns in individual eruptions, for the formation of a transient lunar atmosphere.

\section{Discussion}

The relevant parameters (lava volume, eruption rate, duration, total gas released, gas mass release rate, etc.) for several types and scales of lunar eruptions (short flow, long flow, sinuous rille, and Cobra Head/Schroeter's Valley, the largest known lunar eruption) are shown in Table 1a. For each of the released gas masses we find the properties of the lunar atmosphere that would be created if the gas release rate from the 
302

303

304

305

306

307

308

309

310

311

312

313

314

315

316

317

318

319

320

321

322

323

324

325

326

327

328

329

330

331

332

333

334

335

336

337

338

339

340

341

342

343

344

345

346

347

erupted magma was much greater than the total loss rate of the atmosphere into space by whatever mechanisms were relevant (which we shall show shortly is the case). Using the mean molecular mass $m=\sim 31.4 \mathrm{~kg} / \mathrm{kmol}$ described above, we find the scale height of the resulting atmosphere, $H=(Q T) /(m g)$ where $Q$ is the universal gas constant, $8.314 \mathrm{~kJ}$ $\mathrm{kmol}^{-1} \mathrm{~K}^{-1}, T$ is the mean lunar surface temperature, $\sim 270 \mathrm{~K}$ assuming radiative equilibrium and a $25 \%$ dimmer Sun $\sim 3.5 \mathrm{Ga}$ ago, and $g$ is the acceleration due to gravity at the lunar surface, $1.62 \mathrm{~m} \mathrm{~s}^{-2}$. These values give $H=44.1 \mathrm{~km}$. The surface density of the atmosphere, $\rho_{\mathrm{s}}$, is equal to its mass, $M$, from Table 1a, divided by the volume equivalent to the surface area of the Moon multiplied by the scale height, i.e. $\rho_{\mathrm{s}}=M /\left(4 \pi R^{2} H\right)$ where $R$ is the lunar radius, $1738 \mathrm{~km}$. Finally, the surface pressure is $P_{\mathrm{s}}=\rho_{\mathrm{s}} g H$. Table $1 \mathrm{~b}$ lists the values of $\rho_{\mathrm{s}}$ and $P_{\mathrm{s}}$ corresponding to the eruption types in Table 1a. Assuming the most extreme alternative volatile species mixture suggested in the literature, the sulfur-dominated mixture of Renggli et al. (2017), would increase $m$ by a factor close to 1.5. This would decrease the scale height and increase the surface density of the atmosphere by the same factor, and leave the surface pressure unchanged.

The implied atmospheric gas masses due to the typical types of lunar volcanic activity in Table 1a are of order $10^{12}$ to $10^{13} \mathrm{~kg}$. As part of an extensive review of three possible types of lunar atmosphere, Stern (1999; his section 5.2.2) treated a hypothetical volcanically-induced atmosphere with a total gas mass of $10^{11} \mathrm{~kg}$ and adopted the loss rate calculated by Vondrak (1974) of $10 \mathrm{~kg} \mathrm{~s}^{-1}$. The same loss rate is estimated in a recent more general analysis by Aleinov et al. (2019) treating much more massive, at least $\sim 10^{15}$ $\mathrm{kg}$, atmospheres with surface pressures $>100 \mathrm{~Pa}$. Using a $10 \mathrm{~kg} \mathrm{~s}^{-1}$ loss rate leads to the typical timescales for atmospheric decay, $\tau_{\mathrm{d}}$, shown in Table $1 \mathrm{~b}$, between $\sim 2,000$ and $\sim 6,000$ years. These values need to be compared with the likely intervals between eruptions on the Moon. As shown earlier, with a total volume of volcanics of $V_{\mathrm{t}}=\sim 10^{7}$ $\mathrm{km}^{3}$ (Head and Wilson, 1992; Evans, 2016), a typical erupted volume of $200 \pm 100 \mathrm{~km}^{3}$ (Table 1a), and a total duration of volcanism of $\tau_{\mathrm{d}}=\sim 2 \mathrm{Ga}$, the shortest average interval between eruptions is $\sim 13,000$ to 40,000 years in the early part of the mare volcanism era if eruptive activity decreases with time. Increasing the $2000 \mathrm{ppm}$ magmatic volatile mass fraction used here to the $3400 \mathrm{ppm}$ suggested by Rutherford et al. (2017) would increase the atmospheric mass values in Table 1a by a factor of 1.7, but this would still make the timescale for atmosphere loss a factor of $\sim 4$ less than the average time between eruptions.

What effect does the non-linear release of gas during the four phases of a typical volcanic eruption (Fig. 1a) have on the peak loss of volatiles during an eruption? To address this question, we first look at the magma volume eruption rate as a function of time for an eruption releasing $250 \mathrm{~km}^{3}$ of magma (a medium-scale volume in the $\sim 100$ $300 \mathrm{~km}^{3}$ average eruption volume range described above) and lasting 46 days (about average for the 1-3 month range discussed above) (Fig. 1b). Magma volume flux is clearly highest in the first ten days (Phase 1 and 2), decreasing two orders of magnitude from an initial peak flux of $10^{6} \mathrm{~m}^{3} \mathrm{~s}^{-1}$, to $10^{4} \mathrm{~m}^{3} \mathrm{~s}^{-1}$ after $\sim 10$ days. Magma volume flux remains at this low value for the next 30 days (Phases 3-4) before falling to zero in the last 4 days at the end of the eruption. Thus, $~ 90 \%$ of the total volume of magma erupted is emplaced in Phase 2, the hawaiian phase characterized by maximum magma degassing and volatile loss.

Using the magma volatile species proposed by Rutherford et al. (2017), the percentages of the magma, water, and CO released as a function of time in the same 
eruption are shown in Fig. 1c. Released water closely mimics the erupted magma, unless a significant amount is left trapped in late-stage magma (Phase 4) intruded into earlier flow lobes during flow inflation. If significant inflation occurs, and the inflating gas does not escape, about $95 \%$ of the water would be released instead of $100 \%$ as shown in Fig. 1c. The $\mathrm{CO}$ in the magma, preferentially released at very great depth, does not all escape: $\mathrm{CO}$ released in Phase 4 does not have time to reach the surface before the conduit freezes, even allowing for bubble coalescence and rise. However, this only represents a few percent of the total $\mathrm{CO}$ and so almost all of the total is released.

In summary, the implied intervals between typical lunar eruptions, 13,000 to 40,000 years, are 6-7 times greater than the likely durations of the vast majority of individual transient atmospheres, between $\sim 2,000$ and 6,000 years. Only for the single, extreme example of Cobra Head/Schroeter's Valley are the time scales comparable. Otherwise, only if all of the Moon's $\sim 10^{7} \mathrm{~km}^{3}$ of basaltic volcanism were to have taken place within a $300 \mathrm{Ma}$ interval would the time scales generally be comparable. The nonlinear release of gas during the four phases of a single eruption do not alter this conclusion; even though volatile release is concentrated in the first $25-35 \%$ of the eruption, the long repose periods between eruptions preclude sufficient buildup to create an enduring atmosphere. The same is true of leakage of gas from magma reservoirs between eruptions: if half of a typical magma volatile inventory is released uniformly over the $\sim 40 \mathrm{ka}$ average interval between eruptions, the leakage rate is somewhat less than $1 \mathrm{~kg} \mathrm{~s}^{-1}$, an order of magnitude less than the atmospheric loss rate.

\section{Conclusions}

On the basis of our analysis of the generation, ascent and eruption of lunar mare basalt magmas and forward-modeling individual eruptions, we conclude that it is very unlikely that the Moon had a semi-permanent (as long as $~ 70 \mathrm{Ma}$ ) volcanically-driven atmosphere as proposed by Needham and Kring (2017), even during a period of peak volcanic flux in early lunar history. We attribute the differences between our estimates and those of Needham and Kring (2017) (see discussion in Supporting Material) to their use of maximum impact basin depths as average depths, and assignment of all excess volumes below datable units to one age (e.g., $5.9 \times 10^{6} \mathrm{~km}^{3}$ assigned to $3.5 \mathrm{Ga}$ in the case of Imbrium).

We also conclude that these low volatile release volumes and rates are not conducive to optimizing the transport of released volatiles from the eruption site to the poles to enhance the accumulation of volatiles in polar cold traps (see also Aleinov et al., 2019), nor of creating temporary environments that might favor astrobiological activity (Schulze-Makuch and Crawford, 2018). Our results suggest that most volatiles in lunar polar cold traps originated from volatile-rich impacts, rather than volatile release from volcanic eruptions, similar to findings about polar cold-trap volatile deposits on Mercury (e.g., Ernst et al., 2018; Deutsch et al., 2019, 2020). This issue could be clarified for the Moon by in situ $\mathrm{D} / \mathrm{H}$ ratio measurements. In order to refine our volcanic emission estimates, future lunar exploration goals should include further analysis of detailed lava flow thicknesses, ages, volumes, volatile contents and repose periods, as well as better determination of the interior structure of mare deposits in large impact basins. 
393 Acknowledgements: We gratefully acknowledge financial support from: the NASA 394 Lunar Reconnaissance Orbiter (LRO) Mission, Lunar Orbiter Laser Altimeter (LOLA) 395 Experiment Team (JWH); the Leverhulme Trust for funding through an Emeritus

396 Fellowship (LW); the NASA Harriett G. Jenkins Graduate Fellowship (Grant Number 397 80NSSC19K1289) (AND). No new data were produced or archived in this analysis. 


\section{References}

Aleinov, I., Way, M. J., Harman, C., Tsigaridis, K., Wolf, E. T., \& Gronoff, G. (2019). Modeling a transient secondary paleolunar atmosphere: 3-D simulations and analysis. Geophysical Research Letters, 46(10), 5107-5116. https://doi.org/10.1029/2019g1082494

Benna, M., Mahaffy, P. R., Halekas, J. S., Elphic, R. C., \& Delory, G. T. (2015). Variability of helium, neon, and argon in the lunar exosphere as observed by the LADEE NMS instrument. Geophysical Research Letters, 42(10), 3723-3729. https://doi.org/10.1002/2015g1064120

Chen, Y., Zhang, Y., Liu, Y., Guan, Y., Eiler, J., \& Stolper, E. (2015). Water, fluorine, and sulfur concentrations in the lunar mantle. Earth and Planetary Science Letters, 427, 37-46. https://doi.org/10.1016/j.eps1.2015.06.046

Cook, J. C., Stern, S. A., Feldman, P. D., Gladstone, G. R., Retherford, K. D., \& Tsang, C. C. C. (2013). New upper limits on numerous atmospheric species in the native lunar atmosphere. Icarus, 225(1), 681687. https://doi.org/10.1016/j.icarus.2013.04.010

Deutsch, A. N., Head III, J. W., \& Neumann, G. A. (2019). Age constraints of Mercury's polar deposits suggest recent delivery of ice. Earth and Planetary Science Letters, 520, 26-33. https://doi.org/10.1016/j.epsl.2019.05.027

Deutsch, A. N., Head III, J. W., Parman, S. W., Wilson, L., Neumann, G. A., \& Lowden, F. (2020). The mass flux of volatiles from effusive eruptions on Mercury. Lunar and Planetary Science Conference, LI, abstract 2259.

Eke, V. R., Teodoro, L. F. A., \& Elphic, R. C. (2009). The spatial distribution of polar hydrogen deposits on the Moon. Icarus, 200, 12-18. https://doi.org/10.1016/j.icarus.2008.10.013

Ernst, C. M., Chabot, N. L., \& Barnouin, O. S. (2018), Examining the Potential Contribution of the Hokusai Impact to Water Ice on Mercury. Journal of Geophysical Research, 123(10), 2628-2646. https://doi.org/10.1029/2018JE005552

Evans, A. J., Soderblom, J. M., Andrews-Hanna, J. C., Solomon, S. C., \& Zuber, M. T. (2016). Identification of buried lunar impact craters from GRAIL data and implications for the nearside maria. Geophysical Research Letters, 43. https://doi.org/10.1002/2015GL067394

Gaillard, F., \& Scaillet, B. (2014). A theoretical framework for volcanic degassing chemistry in a comparative planetology perspective and implications for planetary atmospheres. Earth and Planetary Science Letters, 403, 307-316. https://doi.org/10.1016/j.eps1.2014.07.009

Hauri, E. H., Weinreich, T., Saal, A. E., Rutherford, M. C., \& Van Orman, J. A. (2011), High pre-eruptive water contents preserved in lunar melt inclusions. Science, 333(6039), 213-215. https://doi.org/10.1126/science.1204626

Head III, J. W., \& Wilson, L. (2017). Generation, ascent and eruption of magma on the Moon: New insights into source depths, magma supply, intrusions and effusive/explosive eruptions (part 2: observations). Icarus, 283, 176-223. https://doi.org/10.1016/j.icarus.2016.05.031

Head III, J. W., Wilson, L., Hiesinger, H., van der Bogert, C. H., Chen, Y., Dickson, J. L., et al. (2020). Lunar volcanism: Volcanic features and processes, in New Views of the Moon (2), edited, in review.

Head, J. W., \& Wilson, L. (1981). Lunar sinious rille formation by thermal erosion: Eruption conditions, rates and durations. Lunar and Planetary Science Conference, XII, 427-429.

Head, J. W., \& Wilson, L. (1992). Lunar mare volcanism: Stratigraphy, eruption conditions, and the evolution of secondary crusts, Geochimica et Cosmochimica Acta, 56(6), 2155-2175. 
454

455

456

457

458

459

460

461

462

463

464

465

466

467

468

469

470

471

472

473

474

475

476

477

478

479

480

481

482

483

484

485

486

487

488

489

490

491

492

493

494

495

496

497

498

499

500

501

502

503

504

505

506

507

508

509

Hiesinger, H., Head, J. W., Wolf, U., Jaumann, R., \& Neukum, G. (2011). Ages and stratigraphy of lunar mare basalts: A synthesis. In W. A. Ambrose and D. A. Williams (Eds.), Recent Advances and Current Research Issues in Lunar Stratigraphy (pp. 1-51). Geological Society of America Special Paper 477.

Kring, D. A. (2014). Production of volatiles at lunar pyroclastic volcanic vents. Annual Meeting of the Lunar Science Exploration Group., abstract 3056.

Livengood, T. A., Mitrofanov, I. G., Chin, G., Boynton, W. V., Bodnarik, J. G., Evans, L. G., et al. (2018). Background and lunar neutron populations detected by LEND and average concentration of near-surface hydrogen near the Moon's poles. Planetary and Space Science, 162, 89-104.

https://doi.org/10.1016/j.pss.2017.12.004

Needham, D. H., \& Kring, D. A. (2017). Lunar volcanism produced a transient atmosphere around the ancient Moon. Earth and Planetary Science Letters, 478, 175-178.

https://doi.org/10.1016/j.eps1.2017.09.002

Ni, P., Zhang, Y., Chen, S., \& Gagnon, J. (2019). A melt inclusion study on volatile abundances in the lunar mantle. Geochimica et Cosmochimica Acta, 249, 17-41.

https://doi.org/10.1016/j.gca.2018.12.034

Newcombe, M. E., Brett, A., Beckett, J. R., Baker, M. B., Newman, S., Guan, Y., Eiler, J. M., \& Stolper, E. M. (2017). Solubility of water in lunar basalt at low $p \mathrm{H}_{2} \mathrm{O}$. Geochimica et Cosmochimica Acta, 200, 330352. https://doi.org/10.1016/j.gca.2016.12.026

Parfitt, E. A., \& Wilson, L. (1995). Explosive volcanic eruptions-IX. The transition between Hawaiianstyle lava fountaining and Strombolian explosive activity. Geophysical Journal International, 121, 226232.

Pasckert, J. H., Hiesinger, H., \& van der Bogert, C. H. (2015). Small-scale lunar farside volcanism. Icarus, 257, 336-354. https://doi.org/10.1016/j.icarus.2015.04.040

Renggli, C. J., King, P. L., Henley, R. W., \& Norman, M. D. (2017). Volcanic gas composition, metal dispersion and deposition during explosive volcanic eruptions on the Moon. Geochimica et Cosmochimica Acta, 206, 296-311. https://doi.org/10.1016/j.gca.2017.03.012

Rutherford, M. J., \& Papale, P. (2009). Origin of basalt fire-fountain eruptions on Earth versus the Moon, Geology, 37(3), 219-222. https://doi.org/10.1130/G25402a.1

Rutherford, M. J., Head III, J. W., Saal, A. E., Hauri, E. H., \& Wilson, L. (2017). Model for the origin, ascent and eruption of lunar picritic magmas. American Mineralogist, 102, 2045-2053.

https://doi.org/10.2138/am-2017-5994

Saal, A. E., Chaussidon, M., Gurenko, A. A., \& Rutherford, M. J. (2018). Boron and lithium contents and isotopic composition of the lunar volcanic glasses. Lunar and Planetary Science Conference, 49, abstract 2575 .

Saal, A. E., Hauri, E. H., Lo Cascio, M., Van Orman, J. A., Rutherford, M. C., \& Cooper, R. F. (2008). Volatile content of lunar volcanic glasses and the presence of water in the Moon's interior. Nature, 454(7201), 192-195. https://doi.org/10.1038/nature07047

Schulze-Makuch, D., \& Crawford, I. A. (2018). Was there an early habitability window for Earth's Moon? Astrobiology, 18(8), 985-988. https://doi.org/10.1089/ast.2018.1844

Shearer, C. K., Hess, P. C., Wieczorek, M. A., Pritchard, M. E., Parmentier, E. M., Borg, L. E., et al. (2006). Thermal and magmatic evolution of the moon. Reviews in Mineralogy and Geochemistry, 60, 365- 
518. https://doi.org/10.2138/rmg.2006.60.4

Solomon, S. C., \& Head III, J. W. (1980). Lunar mascon basins: Lava filling, tectonics and evolution of the lithosphere. Reviews of Geophysics and Space Physics, 18(1), 107-141.

Stern, S. A. (1999). The lunar atmosphere: History, status, current problems, and context. Reviews of Geophysics, 37(4), 453-491. https://doi.org/10.1029/1999rg900005

Vondrak, R. R. (1974). Creation of an artificial lunar atmosphere. Nature, 248(5450), 657-659. https://doi.org/10.1038/248657a0

Wallace, P. J., Plank, T., Edmonds, M., \& Hauri, E. H. (2015). Volatiles in magmas. In H. Sigurdsson (Ed.), The Encyclopedia of Volcanoes (pp. 163-183). London, UK: Elsevier, Inc.

Weider, S. Z., Crawford, I. A., \& Joy, K. H. (2010). Individual lava flow thicknesses in Oceanus Procellarum and Mare Serenitatis determined from Clementine multispectral data. Icarus, 209(2), 323-336. https://doi.org/10.1016/j.icarus.2010.05.010

Whitten, J. L., \& Head III, J. W. (2015a). Lunar cryptomaria: Mineralogy and composition of ancient volcanic deposits. Planetary and Space Science, 106, 67-81. https://doi.org/10.1016/j.pss.2014.11.027

Whitten, J. L., \& Head III, J. W. (2015b). Lunar cryptomaria: Physical characteristics, distribution, and implications for ancient volcanism. Icarus, 247, 150-171. https://doi.org/10.1016/j.icarus.2014.09.031

Wieczorek, M. A., Neumann, G. A., Nimmo, F., Kiefer, W. S., Taylor, G. J., Melosh, H. J., et al. (2013). The crust of the Moon as seen by GRAIL. Science, 339(6120), 671-675.

https://doi.org/10.1126/science.1231530

Wilson, L., \& Head III, J. W. (1981). Ascent and eruption of basaltic magma on the Earth and Moon. Journal of Geophysical Research, 86(B4), 2971-3001.

Wilson, L., \& Head III, J. W. (2003). Deep generation of magmatic gas on the Moon and implications for pyroclastic eruptions. Geophysical Research Letters, 30(12). https://doi.org/10.1029/2002GL016082

Wilson, L., \& Head III, J. W. (2017). Generation, ascent and eruption of magma on the Moon: New insights into source depths, magma supply, intrusions and effusive/explosive eruptions (Part 1: Theory). Icarus, 283, 146-175. https://doi.org/10.1016/j.icarus.2015.12.039

Wilson, L., \& Head III, J. W. (2018). Controls on lunar basaltic volcanic eruption structure and morphology: Gas release patterns in sequential eruption phases. Geophysical Research Letters, 45, 58525859. https://doi.org/10.1029/2018GL078327

Wilson, L., Head III, J. W., \& Zhang, F. (2019). A theoretical model for the formation of Ring Moat Dome Structures: Products of second boiling in lunar basaltic lava flows. Journal of Volcanology and Geothermal Research, 374, 160-180. https://doi.org/10.1016/j.jvolgeores.2019.02.018

\section{Additional References in Supporting Material}

Baker, D. M. H., \& Head III, J. W. (2013). New morphometric measurements of craters and basins on Mercury and the Moon from MESSENGER and LRO altimetry and image data: An observational framework for evaluating models of peak-ring basin formation. Planetary and Space Science, 86, 91-116. https://doi.org/10.1016/j.pss.2013.07.003

Baker, D. M. H., \& Head III, J. W. (2015). Constraints on the depths of origin of peak rings on the Moon from Moon Mineralogy Mapper data. Icarus, 258, 164-180. https://doi.org/10.1016/j.icarus.2015.06.013 
Baker, D. M. H., Head III, J. W., Neumann, G. A., Smith, D. E., \& Zuber, M. T. (2012). The transition from complex craters to multi-ringed basins on the Moon: Quantitative geometric properties from Lunar Reconnaissance Orbiter Lunar Orbiter Laser Altimeter (LOLA) data. J. Geophys. Res., 117, E00H16. https://doi.org/10.10.29/2011JE004021

Gong, S. X., Wieczorek, M. A., Nimmo, F., Kiefer, W. S., Head III, J. W., Huang, C. L., Smith, D. E., \& Zuber, M. T. (2016). Thicknesses of mare basalts on the Moon from gravity and topography. Journal of Geophysical Research, 121(5), 854-870. https://doi.org/10.1002/2016je005008

Head III, J. W. (1974). Orientale multi-ringed basin interior and implications for the petrogenesis of lunar highland samples. The Moon, 11, 327-356, 1974.

Head III, J. W. (1982). Lava flooding of ancient planetary crusts: Geometry, thickness, and volumes of flooded lunar impact basins. The Moon and the Planets, 26, 61-88.

Head, J. W., \& Lloyd, D. D. (1971). Near Terminator Photography. Apollo 14 Preliminary Science Report $S P-272,297-300$, NASA Special Publication.

Hiesinger, H., Head III, J. W., Wolf, U., Jaumann, R., \& Neukum, G. (2002). Lunar mare basalt flow units: Thicknesses determined from crater size-frequency distributions. Geophysical Research Letters, 29(8). https://doi.org/10.1029/2002GL014847

Horz, F. (1978). How thick are lunar mare basalts? Proceedings $9^{\text {th }}$ Lunar and Planetary Science Conference, 3 (pp. 3311-3331). New York, NY: Pergamon Press, Inc.

Howard, K. A., Wilhelms, D. E., \& Scott, D. H. (1974). Lunar basin formation and highland stratigraphy. Reviews of Geophysics and Space Physics, 12, 309-327. https://doi.org/10.1029/RG012i003p00309

Johnson, B. C., Blair, D. M., Collins, G. S., Melosh, H. J., Freed, A. M., Taylor, G. J., et al. (2016). Formation of the Orientale lunar multiring basin., Science, 354, 441-444. https://doi.org/10.1126/science.aag0518

Lloyd, D., \& Head, J. W. (1972). Orientale basin deposits (Riccioli area) in Apollo 16 earthshine photography. In Apollo 16 Preliminary Science Report, NASA Spec. Pap., SP-315 (pp. 29-24-29-26). Washington, DC: National Aeronautics and Space Administration.

Neumann, G. A., Zuber, M. T., Wieczorek, M. A., Head, J. W., Baker, D. M. H., Solomon, S. C., et al. (2015). Lunar impact basins revealed by Gravity Recovery and Interior Laboratory measurements. Science Advances, 1, 1-10. https://doi.org/10.1126/sciadv.1500852

Robinson, M. S., Ashley, J. W., Boyd, A. K., Wagner, R. V., Speyerer, E. J., Hawke, B. R., et al. (2012). Confirmation of sublunarean voids and thin layering in mare deposits. Planet Space Sci, 69(1), 18-27. https://doi.org/10.1016/j.pss.2012.05.008

Rutherford, M. J., Head III, J. W., Saal, A. E., Hauri, E. H., \& Wilson, L. (2017). Model for the origin, ascent and eruption of lunar picritic magmas. American Mineralogist, 102, 2045-2053. https://doi.org/10.2138/am-2017-5994

Schaber, G. G. (1973). Lava flows in Mare Imbrium: Geologic evaluation from Apollo orbital photography. Proceedings of the $4^{\text {th }}$ Lunar Planetary Science Conference (73-92).

Smith, D. E., Zuber, M. T., Neumann, G. A., Lemoine, F. G., Mazarico, E., Torrence, M. H., et al. (2010). Initial observations from the Lunar Orbiter Laser Altimeter (LOLA). Geophysical Research Letters, 37, L18204. https://doi.org/10.1029/2010GL043751

Solomon, S. C., \& Head III, J. W. (1979), Vertical movement in mare basins: Relation to mare 
622 emplacement, basin tectonics and lunar thermal history. Journal of Geophysical Research, 84(B4), 1667-

6231682.

624

625

626

627

628

629

630

631

632

633

634

635

Spudis, P. D. (1993). The Geology of Multiring Impact Basins: The Moon and Other Planets, Cambridge University Press: Cambridge, England.

Spudis, P. D., Wilhelms, D. E., \& Robinson, M. S. (2011) The Sculptured Hills of the Taurus Highlands: implication for the relative age of Serenitatis, basin chronologies and the cratering history of the Moon. Journal of Geophysical Research, 116, E00H03, https://doi.org/10.1029/2011JE003903

Stöffler, D., Ryder, G., Ivanov, B. A., Artemieva, N. A., Cintala, M. J., \& Grieve, R. A. F. (2006). Cratering history and lunar chronology. Reviews in Mineralogy and Geochemistry, 60, 519-596. https://doi.org/10.2138/rmg.2006.60.05

Thomson, B. J., Grosfils, E. B., Bussey, D. B. J., \& Spudis, P. D. (2009). A new technique for estimating the thickness of mare basalts in Imbrium Basin. Geophysical Research Letters, 36(12), L12201, https://doi.org/10.1029/2009g1037600

Whitten, J., Head III, J. W., Staid, M. I., Pieters, C. M., Mustard, J. F., Clark, R., et al. (2011). Lunar mare deposits associated with the Orientale impact basin: New insights into mineralogy, history, mode of emplacement, and relation to Orientale Basin evolution from Moon Mineralogy Mapper (M3) data from Chandrayaan-1. Journal of Geophysical Research, 116. https://doi.org/10.1029/2010JE003736

Whitten, J. L., \& Head III, J. W. (2013). Detecting volcanic resurfacing of heavily cratered terrain: Flooding simulations on the Moon using Lunar Orbiter Laser Altimeter (LOLA) data. Planetary and Space Science, 85, 24-37. https://doi.org/10.1016/j.pss.2013.05.013

Williams, K. K., \& Zuber, M. T. (1998). Measurement and analysis of lunar basin depths from Clementine altimetry. Icarus, 131(1), 107-122. https://doi.org/10.1006/icar.1997.5856

Yingst, R. A., \& Head III, J. W. (1997). Volumes of lunar lava ponds in South Pole-Aitken and Orientale Basins: Implications for eruption conditions, transport mechanisms and magma source regions. Journal of Geophysical Research, 102(E5), 10,909-10,931.

Zuber, M. T., Smith, D. E., Watkins, M. M., Asmar, S. W., Konopliv, A. S., Lemoine, F. G., et al. (2013). 339(6120), 668-671. https://doi.org/10.1126/science.1231507

Zuber, M. T., Smith, D. E., Neumann, G. A., Goossens, S., Andrews-Hanna, J. C., Head, J. W., et al. (2016). Gravity field of the Orientale basin from the Gravity Recovery and Interior Laboratory Mission. 663 Science, 354, 438-441. https://doi.org/10.1126/science.aag0519 
Table 1a. Parameters of various types of lunar eruption. Cobra Head is the source vent of Schroeter's Valley (Head and Wilson, 2017). Released volatiles assumed to have molecular mass $31.4 \mathrm{~kg} \mathrm{kmol}^{-1}$ and to form $n=2000 \mathrm{ppm}$ by mass of a magma that has a liquid density $\rho_{\mathrm{m}}=3000 \mathrm{~kg} \mathrm{~m}^{-3} . V=$ lava volume; $F_{1}=$ lava volume eruption rate; $\tau_{\mathrm{e}}=$ eruption duration; $M_{\mathrm{g}}=$ total gas mass released; $F_{\mathrm{g}}=$ gas mass release rate. Typical values for parameters are quoted but individual eruption values may vary by a factor of at least 2 to 3.

\begin{tabular}{llllll} 
Feature & $V / \mathrm{km}^{3}$ & $F_{\mathrm{l}} /\left(\mathrm{m}^{3} \mathrm{~s}^{-1}\right)$ & $\tau_{\mathrm{e}} /$ days & $M_{\mathrm{g}} / \mathrm{kg}$ & $F_{\mathrm{g}} /\left(\mathrm{kg} \mathrm{s}^{-1}\right)$ \\
\hline Cobra Head & 2000 & $1.4 \times 10^{5}$ & 150 & $1.2 \times 10^{13}$ & $9.3 \times 10^{5}$ \\
Long flow & 300 & $\sim 10^{5}$ & 30 & $1.8 \times 10^{12}$ & $6.9 \times 10^{5}$ \\
Small flow & 200 & $\sim 10^{4}$ & 100 & $1.2 \times 10^{12}$ & $1.4 \times 10^{5}$ \\
Sinuous rille & 100 & $\sim 3 \times 10^{4}$ & 50 & $\sim 6 \times 10^{11}$ & $1.4 \times 10^{5}$
\end{tabular}

Table 1b. Initial values of the surface density, $\rho_{\mathrm{s}}$, and surface pressure, $P_{\mathrm{s}}$, in a transient atmosphere produced by the four types of volcanic activity listed in Table 1a. The maximum duration of the atmosphere, $\tau_{\mathrm{d}}$, is indicated.

\begin{tabular}{llll} 
Feature & $\rho_{\mathrm{s}} /\left(\mathrm{kg} \mathrm{m}^{-3}\right)$ & $P_{\mathrm{s}} / \mathrm{Pa}$ & $\tau_{\mathrm{d}} /$ years \\
\hline Cobra Head & $7.2 \times 10^{-6}$ & 0.51 & 38,000 \\
Long flow & $1.1 \times 10^{-6}$ & $7.7 \times 10^{-2}$ & 5,700 \\
Small flow & $7.2 \times 10^{-7}$ & $5.1 \times 10^{-2}$ & 3,800 \\
Sinuous rille & $3.6 \times 10^{-7}$ & $2.6 \times 10^{-2}$ & 1,900
\end{tabular}


Figure 1a-c. 


\begin{tabular}{|c|c|c|c|c|}
\hline & PHASE 1 & PHASE 2 & PHASE 3 & PHASE 4 \\
\hline $\begin{array}{c}\text { Eruption } \\
\text { Phase }\end{array}$ & $\begin{array}{c}\text { Dike } \\
\text { penetrates } \\
\text { to surface, } \\
\text { transient gas } \\
\text { release } \\
\text { phase }\end{array}$ & $\begin{array}{c}\text { Dike base } \\
\text { still rising, } \\
\text { high flux } \\
\text { hawaiian } \\
\text { eruptive } \\
\text { phase }\end{array}$ & $\begin{array}{c}\text { Dike } \\
\text { equilibration, } \\
\text { lower flux } \\
\text { hawaiian to } \\
\text { strombolian } \\
\text { transition } \\
\text { phase } \\
\end{array}$ & $\begin{array}{c}\text { Dike closing, } \\
\text { strombolian } \\
\text { vesicular } \\
\text { flow phase }\end{array}$ \\
\hline \multirow{2}{*}{$\begin{array}{c}\text { Dike } \\
\text { Configuration }\end{array}$} & Crust & & & \\
\hline & Mantle & & $v$ & \\
\hline \multirow{3}{*}{$\begin{array}{c}\text { Surface } \\
\text { Eruption } \\
\text { Style }\end{array}$} & \multirow{2}{*}{$\begin{array}{c}\text { Transparent } \\
\text { gas }\end{array}$} & $\begin{array}{l}\text { Opaque pyroclastic } \\
\text { fountain }\end{array}$ & \multirow{2}{*}{$\begin{array}{c}\begin{array}{c}\text { Fountain } \\
\text { declines } \\
\text { toward } \\
\text { strombolian }\end{array} \\
\text { sto }\end{array}$} & $\begin{array}{l}\text { a) Proximal } \\
\text { foam flow }\end{array}$ \\
\hline & & & & $\begin{array}{l}\text { b) Distal flow } \\
\text { inflation }\end{array}$ \\
\hline & & $\begin{array}{l}\text { Lava } \\
\text { lake }\end{array}$ & 70 & 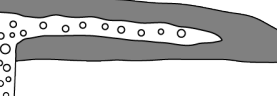 \\
\hline $\begin{array}{l}\text { Magma Rise } \\
\text { Speed }\end{array}$ & 30 to $20 \mathrm{~m} / \mathrm{s}$ & 20 to $10 \mathrm{~m} / \mathrm{s}$ & 5 to $<1 \mathrm{~m} / \mathrm{s}$ & $<1 \mathrm{~m} / \mathrm{s}$ \\
\hline $\begin{array}{c}\text { Magma } \\
\text { Volume Flux }\end{array}$ & $\sim 10^{6} \mathrm{~m}^{3} / \mathrm{s}$ & $10^{6}$ to $10^{5} \mathrm{~m}^{3} / \mathrm{s}$ & $10^{5}$ to $\sim 10^{4} \mathrm{~m}^{3} / \mathrm{s}$ & $\sim 10^{4} \mathrm{~m}^{3} / \mathrm{s}$ \\
\hline $\begin{array}{l}\text { Percent Dike } \\
\text { Volume } \\
\text { Erupted }\end{array}$ & $<5 \%$ & $\sim 80 \%$ & $\sim 5 \%$ & $\sim 10 \%$ \\
\hline $\begin{array}{l}\text { Phase } \\
\text { Duration }\end{array}$ & $\sim 3$ minutes & $\sim 4$ day & $\sim 6$ day & $\sim 30$ days \\
\hline
\end{tabular}

$1 a$

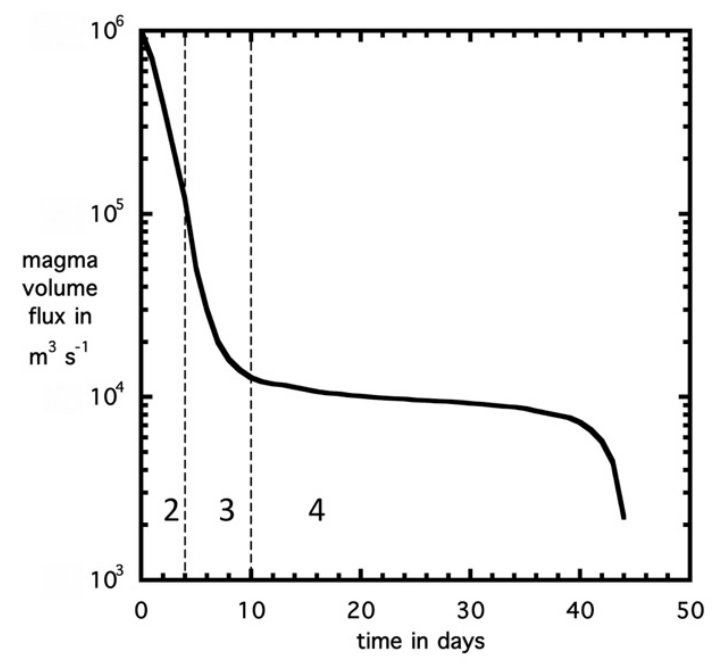

$1 b$

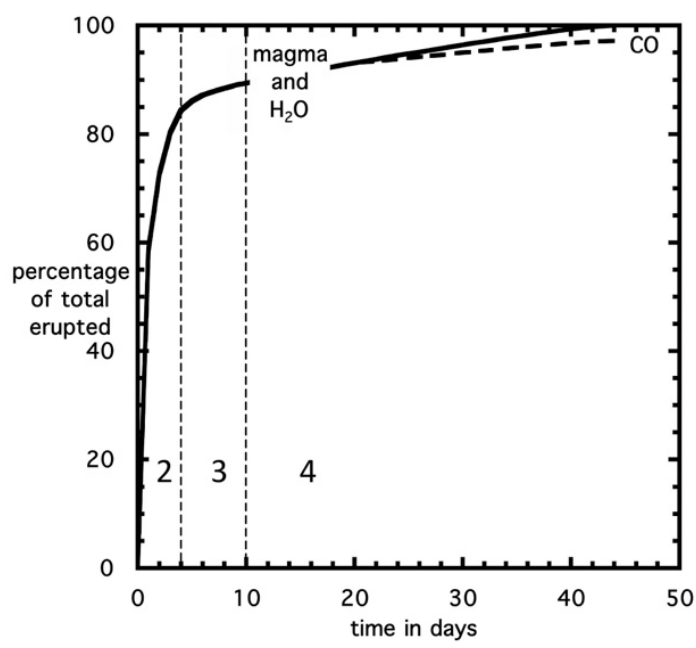

$1 c$ 


\title{
Supporting Material for
}

\section{"Volcanically-Induced Transient Atmospheres on the Moon: Assessment of Duration, Significance and Contributions to Polar Volatile Traps"}

\author{
James W. Head ${ }^{1}$, Lionel Wilson ${ }^{1,2}$, Ariel N. Deutsch ${ }^{1}$, \\ Malcolm J. Rutherford ${ }^{1}$, Alberto E. Saal ${ }^{1}$
}

${ }^{1}$ Department of Earth, Environmental and Planetary Sciences, Brown University, Providence, RI 02912 USA.

${ }^{2}$ Lancaster Environment Centre, Lancaster University, Lancaster LA1 4YQ UK.

Analysis and Assessment of Procedures and Assumptions:

In this supplementary material, we provide commentary on the major sources of uncertainty in assessing the duration and significance of volcanically-induced transient atmospheres and major sources of uncertainty in the approach, as a guide for comparison to our forward-model gas exsolution estimates in the main text. We summarize the procedures and assumptions used by Needham and Kring (2017) (N\&K) to determine the mare basalt volcanic flux that, together with their volatile exsolution model, is the input into their lunar atmospheric buildup and retention calculations (Fig. S1). We also discuss how future work could help improve these estimates.

Major steps in establishing the atmospheric buildup and retention include 1) estimating the mare basalt volume, (2) determining the mare basalt volcanic flux (volume as a function of time), and (3) estimating the production of lunar volatiles over time.

\section{S1. Estimating the mare basalt volume in each basin}

In order to estimate the total volume of basalt erupted with time, $N \& K$ first tabulate the volumes of basalts erupted into each of the major impact basins (e.g., Imbrium, Serenitatis, etc.) or areas of accumulation (e.g., Oceanus Procellarum) (N\&K, their Table 1). There are various levels of uncertainty pertaining to basin size (assignment of rings in multi-ring basins), the initial and final basin geometry, and the state of degradation and response to the thermal structure of the Moon at the time of basin formation that influence estimates of basalt volume in any particular basin. As discussed by N\&K, there is also a high level of uncertainty in past estimates of the total thickness and volumes of mare basalts in individual basins using different techniques (e.g., Crisium basin estimates differ by $5 \times 10^{5} \mathrm{~km}^{3}$ ).

For most of the major mare basins (in order of decreasing total volume: Imbrium, Serenitatis, Crisium, Humorum, Nectaris, Grimaldi, Smythii), N\&K use the basin depthdiameter estimates of Williams and Zuber (1998) as input into their maximum thickness estimates for their volume calculations; they describe these as generally consistent with the more recent data from LOLA and GRAIL. N\&K augment this with older data (Horz, 1978: Procellarum, Tranquillitatis; Yingst and Head, 1997: South Pole-Aitken) and a more recent study for Orientale (Whitten et al., 2011). These data then represent the 
values for the total mare basalt fill thickness in each of eleven lunar basins (N\&K, their Table 1) (Fig. S2a).

One source of uncertainty with this approach is that the Williams and Zuber (1998) estimates for impact basin geometry and lava fill thicknesses were compiled with low resolution Clementine altimetry data. In addition, N\&K make several assumptions about the initial structure of the basins, and together, these factors tend to very significantly overestimate the total basin volumes in several key cases (e.g., Imbrium, Serenitatis). The Williams and Zuber (1998) maximum thickness estimates (N\&K, their Table 1, column 3 ) are then used by $\mathrm{N} \& \mathrm{~K}$ as average thicknesses to compute the entire mare basalt volume in each of the 11 basins treated by Williams and Zuber (1998) (N\&K, their Table 1, column 4). These 11 total volumes (N\&K, their Table 1, column 4) then account for $44 \%$ of the lunar separate mare accumulation areas considered (11 of 25), but $>95 \%$ of the total global mare basalt volume calculated by N\&K (Fig. S2b).

More specifically, the Williams and Zuber (1998) approach to estimating maximum basalt thickness in each basin is as follows: Clementine LIDAR data are used to calculate the depths of 29 large craters and basins on the Moon; the most well-preserved examples, generally unflooded by mare basalt volcanism, are then compared with previous depth/diameter (d/D) plots, revealing an inflection point in the diameter range characterized by the transition from complex craters to peak-ring basins.

From this relationship, an empirical power law fit is derived for basin depth as a function of increasing size, a relationship characterized by a shallower slope than that of complex craters. The definition of this inflection point is provided by seven peak-ring basins ranging in diameter from 100-200 km. Williams and Zuber (1998) then use this empirical power law basin-scale $d / D$ relationship to estimate the thickness of mare basalt fill in each basin by assuming that the unfilled depths of each basin follow this $d / D$ relationship, and the current mare fill elevation represents the upper bound on the thickness. Thus, the Williams and Zuber (1998) estimated basalt thicknesses for each basin are derived from "the difference between the predicted basin depth and the measured depth of the mare surface." N\&K then use these Williams and Zuber (1998) thickness estimates $(\mathrm{N} \& \mathrm{~K}$, their Table 1, column 3) as input to their basin volume calculations.

Among the sources of uncertainty in the thickness estimates derived by Williams and Zuber (1998) are:

1. Loading and flexure of the basin interior can cause basin subsidence (e.g., Solomon and Head, 1979, 1980), resulting in mare basalt thickness in the basin interior being greater than that predicted by the $\mathrm{d} / \mathrm{D}$ relationship. Williams and Zuber (1998) accounted for this loading-related subsidence in their calculations (their Table 2), and thus this is accounted for in the thicknesses N\&K utilize in their Table 1.

2. Not all of the basins chosen by N\&K to apply the Williams and Zuber (1998) thickness estimates to derive volumes (the 11 basins in their Table 1) were comparable to the most well-preserved and generally unmodified basins used to calculate the empirical power-law fit. A large number of factors can influence basin topography during and subsequent to basin formation: initial lithospheric thermal structure, subsequent viscous relaxation, and impact-induced topographic degradation are all likely to mean that older basins (for example, 
old Tranquillitatis compared with young Imbrium) were shallower than the empirical fit when they began to be filled with mare basalt, resulting in overestimation of the thickness of their fill. Impact degradation can lower rim elevation, emplace ejecta inside the basin, and shallow the floor, all decreasing the basin depth prior to filling with mare basalt. For example, the impact event forming the Imbrium basin emplaced significant thicknesses and volumes of ejecta inside the Serenitatis basin (Spudis et al., 2011), volumes that would need to be subtracted from the total thickness, and thus volume, of Serenitatis mare fill.

3. Scaling depth/diameter relationships to larger basin-scale diameters implies a consistent choice for the crater and basin diameter. Unfortunately, the choice of which ring in multi-ring basins represents the closest approximation to the crater or peak-ring basin rim crest is controversial (see Head, 1974; Howard et al., 1974; Spudis, 1993; Neumann et al., 2015; Zuber et al, 2016; Johnson et al., 2016 , for discussion of this problem) and thus the choice of basin diameter to input into the extrapolation of depth/diameter relationships to larger basin-scale diameters could vary by several tens of percent.

4. Depth/diameter relationships provide data on the maximum depth of the basin, and thus the maximum thickness of the fill, not the average thickness. For example, the Orientale basin has a maximum depth of $>8 \mathrm{~km}$ but the majority of the basin is less than $\sim 2 \mathrm{~km}$ deep (Fig. S3a). The geometry of the interior of multi-ringed basins differs significantly from a cylindrical plug (Fig. S3b). For example, the thickness of mare basalts may differ by a factor of four between the deepest part of the basin interior and the outer area overlying the terrace inside the topographic ring. Volcanic flooding models of the essentially unfilled Orientale basin (Head, 1982) showed that the area between the Inner Rook ring and the Cordillera ring, an area making up more than $70 \%$ of the total area of the basin, had lava thicknesses of less than $2 \mathrm{~km}$, a thickness about $25 \%$ of the deepest part of the basin.

5. There are uncertainties in extrapolating $d / D$ data from the diameter range of peak-ring basins to the much larger scale of multi-ringed basins. Using much improved d/D data from the Lunar Orbiter Laser Altimeter (Smith et al., 2010) and GRAIL gravity data (Zuber et al., 2013), Baker and Head (2013) and Baker et al. (2012) showed that there is a possible further shallowing of the slope of the $d / D$ trend at the multi-ringed basin scale, the diameter of most of the 11 basins considered by Williams and Zuber (1998) and N\&K. This predicted shallowing would result in the thicknesses calculated by the Williams and Zuber (1998) method (N\&K, their Table 1, column 3) being overestimates. Summary of the N\&K tabulation of mare basalt volumes in the 11 major mare basins: In order to derive the total volume of mare basalt in each basin, N\&K use the maximum thickness estimates of William and Zuber (1998) (N\&K, their Table 1, column 3). They assume that this is the average thickness (Fig. S3b), and multiply this maximum thickness by the area inside the basin to derive a total volume of mare basalt in each basin (N\&K, their Table 1, column 4). For example, in the Imbrium basin, N\&K use the thickness of mare basalts determined by Williams and Zuber (1998) derived as follows (Fig. S3b: Imbrium basin extrapolated d/D, minus depth to current mare surface, yields a 
thickness of $4.70 \mathrm{~km}$; adjusting this for loading and subsidence yields a maximum

138 thickness of $5.24 \mathrm{~km}$ for the lava at the center of the Imbrium basin. N\&K then take this maximum thickness, which includes all of the caveats described above predicting that the sign of this value will be an overestimate, and then take two additional steps: 1) they calculate the area of the Imbrium basin to cover $1,010,400 \mathrm{~km}^{2}$, and then assume that the maximum thickness estimate of $5.24 \mathrm{~km}$ is the average thickness over the entire $1,010,400 \mathrm{~km}^{2}$ area of the basin, yielding a total volume of the Imbrium basin mare fill to be $5.295 \times 10^{6} \mathrm{~km}^{3}$ (Fig. S3b). On the basis of using a maximum thickness estimate (very likely to be an overestimate for the reasons stated above) and assuming that it represents the average thickness for the whole basin, we believe that this value significantly overestimates the volume of mare basalt in the Imbrium basin. A similar approach is utilized for each individual basin (N\&K Table 1) suggesting that these values will also be overestimates.

\section{S1.1 Opportunities and prospects for current and future improved estimates}

The major uncertainties in the total volume estimates for each basin derive from lack of detailed knowledge of the underlying geometry of impact basins at the time of their initial mare fill, and their detailed response to topographic filling (loading, flexure and subsidence). New Lunar Orbiter Laser Altimeter (LOLA) and Gravity Recovery and Interior Laboratory (GRAIL) data are the types of data that can help reduce this uncertainty. The acquisition of much higher resolution altimetry data (Lunar Orbiter Laser Altimeter; Smith et al., 2010) and gravity data (GRAIL; Zuber et al., 2013) permitted better understanding of the topography of craters, peak-ring and multi-ring basins (e.g., Baker and Head, 2013, 2015) and an understanding of the three-dimensional structure and lava filling histories of impact craters and basins. For example, Whitten and Head (2013) provided detailed modeling of lava flooding and progressive filling estimates for typical peak-ring basins and degraded multi-ring basins. Evans et al. (2016) used GRAIL gravity data to assess the presence of craters buried by lava filling and the thickness and volume of their fill. LOLA and GRAIL data have also been used to estimate the average thicknesses of mare basalts on the lunar nearside $(0.74 \mathrm{~km})($ Gong et al., 2016). For the future, there is a compelling need for detailed basin-wide geophysical traverse surveys to assess the depth to the mare-basin floor interface, the depth and geometry of the crust-mantle interface, and variations in basin geometry and fill as a function of initial basin age.

\section{S2. Determining the mare basalt volcanic flux (volume of lava extruded as a function of time)}

To convert total estimated mare basalt volumes derived for each basin (as described above) into a volcanic flux (volume as a function of time), the ages of the various mare basalt units need to be determined and their relative abundance assessed. Six steps are needed to accomplish this task: 1) definition of a volcanic unit, and then determination of the 2) area covered by the unit, 3) thickness of the unit, 4) volume of the unit, 5) age of the unit, and finally, 6) duration of its emplacement. Obviously, deriving each of the six factors in these estimates becomes more and more difficult for older and older deposits, as the stratigraphically younger flow units mask the older flow units (Fig. S4). Needham and Kring (2017) use the following set of steps to accomplish this task: 


\section{S2.1. Estimate mare unit area and age}

$\mathrm{N} \& \mathrm{~K}$ use the mare unit boundary mapping and crater size frequency analyses data from Hiesinger et al. (2011) (and others). On the basis of these data they conclude that mare basalt provinces were emplaced from $\sim 3.9$ Ga to as recently as $\sim 1.1 \mathrm{Ga}$.

\section{S2.2. Estimate mare unit thickness}

N\&K note that "observations of specific mare eruptive units indicate an average mare unit thickness of $\sim 250 \mathrm{~m}$ (Weider et al., 2010) within Serenitatis and Oceanus Procellarum..." with this thickness "...expected to incorporate an integrated sequence of thinner flows.... and is assumed to be the average thickness for all surface mare units in the absence of other thickness measurements..." In the analysis of Weider et al. (2010), they identify eight units (their Table 4) with estimated average unit thicknesses ranging from $80-600 \mathrm{~m}$, and derive an average of $250 \mathrm{~m}$ derived by averaging the total of the individual values in their Table 4.

As N\&K acknowledge, spectrally defined flow units can easily be composed of multiple lava flows of similar composition. In addition, the thickness of a flow unit is related to the nature of the underlying topography: flows emplaced in rough terrain such as the interior of craters or the highlands will pond and be much thicker than flows emplaced on a flat or sloping mare plain (e.g., Head, 1982; Whitten and Head, 2013). A wide range of mare basalt flow and unit thickness have been observed or inferred in the relatively flat lunar maria, as follows: 1) 3-5 m from near-terminator images of flow fronts (Head and Lloyd, 1971; Lloyd and Head, 1972); 2) average of 30-35 $\mathrm{m}$ in the flow fronts in the observed young Eratosthenian-aged flow fronts in Mare Imbrium (Schaber, 1973); 3) 30-60 m average thickness (range of 20-220 m) from basalt flow units exposed within the nearside maria, using inflections in impact crater size-frequency distributions (Hiesinger et al., 2002); 4) 10 m average flow thicknesses estimated from exposed sections in impact crater and pit crater walls (Robinson et al., 2012).

On the basis of these estimates, all typically less than $\sim 50 \mathrm{~m}$, we conclude that the average thickness of $250 \mathrm{~m}$ may overestimate the average thickness of individual lava flows by a factor of five. Clearly, average thickness in the initial rough topography of the basin floor may have been larger, but as shown by the interior of Orientale (e.g., Head, 1982; Whitten et al., 2011), these variations will soon tend to smooth out due to emplacement of superposed lavas. An additional factor is that a spectrally defined lava flow unit may be composed of a series of individual lava flows. The values determined by Weider et al. (2010) are for spectrally defined flow units, and thus these are likely to be composed of a series of flow units whose thickness was cumulative. Using this average $250 \mathrm{~m}$ flow thickness to estimate the thickness of all previous dated flow units carries with it the interpretation that these previously dated flow units are likely to be composed of multiple flow units of uncertain age range. This is acknowledged by N\&K, but needs to be kept in mind as one moves forward to the determination of volatile flux in individual eruptions and the contribution of such individual eruptive events to production and retention of a transient atmosphere. For example, if a dated $250 \mathrm{~m}$ thick lava flow unit consists of five separate $50 \mathrm{~m}$ thick eruptive lava flows, what are the thicknesses, volumes and volatile fluxes of each of the individual eruptions, and is the repose period between their emplacement sufficient to cumulatively contribute to the buildup of a transient atmosphere, or do the volatiles dissipate between eruptions? 


\section{S2.3 Estimate mare basalt erupted volume as a function of time}

Step 1: Surface Flows: Needham and Kring (2017) then used the individual mapped mare basalt units and ages (predominantly from Hiesinger et al., 2011) to calculate the volume of surface mare basalts emplaced in each basin as a function of time (their Fig. 2a; reproduced as Fig. S1a). These mapped and dated mare units are exposed at the surface, and thus overlie older units for which only relative ages are available (they are older because they underlie the basalts exposed at the surface) (Fig. S4).

Step 2: Lava Flows Underlying Exposed Surface Flows: Needham and Kring then "assume that the underlying flows were emplaced as older surface flows that were embayed by younger surface flows, such that the mare units are stacks of superposed lava units emplaced via effusive surface eruptions. Although ages of underlying basalts, with volumes taken as the difference between the total mare basalt for a given basin and the volume of the mapped surface flows, are not identified directly, these deposits are at least as old as the oldest surface unit (noted in italics in their Table S1)." (Fig. S4). Without age constraints on the underlying units, it is not possible to accurately describe the timing of the older eruptions. N\&K provide a maximum estimate by assuming that all underlying units erupted at the same time as the surface units.

These underlying units are then dealt with by Needham and Kring in two ways as shown in the following example for the Imbrium basin:

1. The oldest dated mare unit in the Imbrium basin is listed as $3.55 \mathrm{Ga}$ (their Table S1). For the basin maria "with unreported ages of units or of units underlying surface mare with identified ages" (their Table S1 explanation, italicized entries as listed in Table S1), N\&K assign an age to these undated and underlying units that is equal to the age of the oldest flow $(3.55 \mathrm{Ga})$. For Imbrium, this gives 17 units that are $3.55 \mathrm{Ga}$, the age of the oldest dated flow, adding an additional $25,383 \mathrm{~km}^{3}$ of lava emplaced at this age $(3.55 \mathrm{Ga})$. This provides a total volume of "dated flows" (35 basalt units ranging in age from 1.1 to 3.5 Ga with a volume of $221,217 \mathrm{~km}^{3}, 4.3 \%$ of the total Imbrium basin mare fill of 5,294,497 $\mathrm{km}^{3}$ ), plus unreported and underlying surface units (17 units, all assigned the age of the oldest dated unit, $3.55 \mathrm{Ga}$ with a volume of $25,383 \mathrm{~km}^{3}, 0.5 \%$ of the total Imbrium basin mare fill) (summarized as percentages in parentheses in Fig. S4). An exact definition of the "underlying units" is not provided, but it consists of these 17 units (their Table S1, units with ages in italics).

2. In order to account for the rest of the mare basalt basin fill that lies below the dated flows, the undated flows together with the "underlying units", N\&K take the total volume of these flow units $(35+17=52$ units in the case of the Imbrium basin) and subtract this number $\left(252,600 \mathrm{~km}^{3}\right)$ from their total volume of the Imbrium basin derived from using the Williams and Zuber (1998)-based thickness estimate $(\mathrm{N} \& \mathrm{~K}$, their Table 1 , column 3 ) to derive a total volume estimate $\left(5,294,497 \mathrm{~km}^{3} ; \mathrm{N} \& \mathrm{~K}\right.$, their Table 1, column 4), thus identifying $5,041,900 \mathrm{~km}^{3}$ of additional basin fill $(95.2 \%$ of the total Imbrium basin volume) as "excess volume". They then assign all of this remaining "excess volume" ( $95.2 \%$ of the total Imbrium basin fill) to an age of the oldest dated surface flow $(3.55 \mathrm{Ga})$, resulting in $95.2 \%$ of the total Imbrium basin fill having a single age (Fig. S4).

Summary: In summary, N\&K take the total Imbrium basin volume from the Williams 
and Zuber (1998) maximum basalt thickness estimate, assume that it represents the average mare fill thickness in the basin (Fig. S3b), and then subtract the volumes that they have accounted for so far with "dated surface", "undated surface" and "subsurface" flow units (4.8\% of the total Imbrium basin volume), and subtract this total number from the "grand total" implied by adopting the Williams and Zuber number maximum thickness number as the average thickness number. N\&K then assign all of this remaining "excess volume" (95.2\% of the total volume) to an age of emplacement of the oldest dated surface flow, $3.55 \mathrm{Ga}$ (Fig. S2c, S4). This $95.2 \%$ of their estimated total basin volume accounts for virtually all of the $\sim 5.4 \times 10^{6} \mathrm{~km}^{3}$ peak in global mare basalt flux at $\sim 3.55 \mathrm{Ga}$ shown in N\&K Figure $2 \mathrm{a}$ (Figure S1a).

$\mathrm{N} \& \mathrm{~K}$ treat the second largest basin fill volume (the Serenitatis basin) in a similar manner (Fig. S2d). The total Serenitatis basin volume is derived by N\&K using the maximum thickness from Williams and Zuber (1998) as an average thickness (Fig. S3b) (N\&K, their Table 1, column 3), multiplying by the total basin area (N\&K, their Table 1 column 2), to obtain a total basin mare basalt volcanic fill volume of $1,473,679 \mathrm{~km}^{3}$ (N\&K, their Table 1, column 4). They define 23 dated basin units, ranging in age from 2.44-3.81 Ga, that make up a volume of $62,262 \mathrm{~km}^{3}, 4.2 \%$ of the total. They further identify 12 additional units comprised of "undated surface" and "subsurface" flow units, that make up a volume of $23,417 \mathrm{~km}^{3}, 1.6 \%$ of the total Serenitatis basin, and add this to the 23 dated flows, for a total of $85,679 \mathrm{~km}^{3}$, a volume making up $5.8 \%$ of the total Serenitatis basin volume estimated by N\&K (column 4, their Table 1). Finally, they subtract this subtotal from the volume "grand total" derived from using the Williams and Zuber maximum thickness number as an average thickness $\left(1,473,679 \mathrm{~km}^{3}\right.$; their Table 1 column 4), yielding an 'excess volume' of 1,388,000 km $3,94.2 \%$ of the total volume in the Serenitatis basin. This entire "excess volume" is then assigned the age of the oldest dated flow, $3.81 \mathrm{Ga}$, resulting in $\sim 94 \%$ of the total volume in the Serenitatis basin (N\&K, their Table 1, column 4) being assigned to a single emplacement age (3.81 Ga) (Fig. S2d). This $94.2 \%$ accounts for virtually all of the $\sim 1.5 \times 10^{6} \mathrm{~km}^{3}$ peak in global mare basalt flux at $\sim 3.8 \mathrm{Ga}$ shown in Needham and Kring Figure 2a (Figure S1a).

Implications: The assignment of this huge "excess volume" in individual basins (95.2\% of the total Imbrium basin mare basalt volume; $94.2 \%$ of the total Serenitatis basin mare basalt volume) to one specific age (Imbrium $=3.55 \mathrm{Ga}$; Serenitatis $=3.81 \mathrm{Ga}$ ) then forms almost the entire $5.5 \times 10^{6} \mathrm{~km}^{3}$ global peak in the mare basalt flux at $3.5 \mathrm{Ga}$ seen in their Figure 2a and the second peak at $\sim 3.8 \mathrm{Ga}$ in their Figure 2a (Fig. S1a).

\section{S2.4 Opportunities and prospects for current and future improved estimates of mare basalt age assignments and total volumes (flux)}

What are the alternative approaches to the N\&K assignment of the huge "excess volume" to the age of the single oldest dated flow? Instead of assigning 95.2\% of the undated volume in Imbrium to one age one could spread this volume evenly out over the entire time between the approximate formation of the Imbrium basin (about $3.85 \mathrm{Ga}$; see discussion in Stoffler et al., 2006), and the 3.55 age (oldest dated surface flow), reducing the peak down to $<2 \times 10^{6} \mathrm{~km}^{3}$, spread out over 250-300 Ma (compare this to their Fig. 2a; Fig. S1a here). In another approach, Thompson et al. (2009) used superposed craters penetrating through the mare basalt to derive a total volume for the Imbrium basin mare basalt fill of $1.3 \times 10^{6} \mathrm{~km}^{3}$. The Thompson et al. (2009) value is only $25 \%$ of the 
321 Needham and Kring total volume value $\left(5.295 \times 10^{6} \mathrm{~km}^{3}\right)$. Future exploration to address 322 this uncertainty should involve a sample return mission to the ejecta of crater penetrating the entire mare fill, and regional geophysical surveys to establish subsurface stratigraphy and structure.

\section{S3. Production of Lunar Volatiles Over Time}

N\&K now take the total "Volume of erupted basalts as a function of time, indicating peak volcanic activity primarily in the Imbrium basin ca. 3.5 Ga." (their Fig. 2a; Fig. S1a here) and calculate the "Mass of volatiles, primarily CO and S, degassed during mare emplacement...." (their Fig. 2b; our Fig S1b here). In order to convert the mare basalt fluxes, as discussed above, to a production function for volatiles released over time, N\&K first estimate the proportion of volatiles degassed during mare emplacement (their Table 2 ), using maximum and minimum values reported in the literature for five species (CO, $\mathrm{H}_{2} \mathrm{O}, \mathrm{H}_{2}, \mathrm{OH}$ and $\mathrm{S}$ ). They then estimate the percent of each gas species liberated from a unit mass $\left(\mathrm{CO}, 100 \% ; \mathrm{H}_{2} \mathrm{O}, 90 \% ; \mathrm{H}_{2}, 100 \% ; \mathrm{OH}, 99 \% ; \mathrm{S}, 90 \%\right)$, and then convert this to maximum and minimum degassed masses of gas for each species in ppm (their Table 2). The "mass of erupted lava was then calculated by multiplying the estimated volume by the bulk density of typical mare basalt $\left(\sim 3.00 \mathrm{~g} / \mathrm{cm}^{3}\right)$." and this mass was then multiplied by the minimum and maximum contents of each mare basalt volatile species as listed in their Table 2. This approach enabled the determination of "the mass range of each volatile released during an eruption".

The next step taken by Needham and Kring was to assess "Incremental production... calculated for mare volumes erupted every 0.1 Ga." Their Table S3 shows that a grand summed total of $8,900,775 \mathrm{~km}^{3}$ of mare lava was erupted on the Moon; $61.2 \%$ of this total $\left(5,446,355 \mathrm{~km}^{3}\right)$ was erupted at the $100 \mathrm{Ma}$ interval centered at $3.5 \mathrm{Ga}$, and of this $61.2 \%, 93.5 \%$ was erupted in the Imbrium basin. Finally, $99.5 \%$ of this total erupted volume was "undated" and "excess" lava, underlying the four oldest dated flow units in Imbrium (3.5-3.55 Ga, 24,031 km ${ }^{3}$ ) (Fig. S2c): on the basis of Needham and Kring approach outlined above, all of this $99.5 \%$ was assigned the age of the oldest flow, 3.5 Ga.

Their Table S3 also shows that, of the grand summed total of $8,900,775 \mathrm{~km}^{3}$ of mare lava erupted on the Moon, $17 \%$ of this total $\left(1,525,044 \mathrm{~km}^{3}\right)$ was erupted in the $100 \mathrm{Ma}$ interval centered at $3.8 \mathrm{Ga}$, and of this $17 \%, 92.6 \%$ was erupted in the Serenitatis basin. Finally, $99.5 \%$ of this total volume erupted in Serenitatis was "undated" and "excess" lava, underlying the oldest dated flow unit in Serenitatis $\left(3.85 \mathrm{Ga}, 621 \mathrm{~km}^{3}\right)$ (Fig. S2d): on the basis of N\&K approach outlined above, all of this $99.5 \%$ was assigned the age of the oldest flow, $3.85 \mathrm{Ga}$.

Needham and Kring then use these data in order to derive the "Mass and surface pressure of volatiles degassed by lunar mare basalt as a function of time" (their Table S3). The results are plotted in their Figure 2c (Fig. S1c here), the "Atmospheric surface pressure resulting from the volatiles released during mare emplacement, with a peak pressure $\sim 1 \%$ of Earth's current atmospheric pressure corresponding to peak volcanic activity $3.5 \mathrm{Ga}$."

Summary: On the basis of this assessment and analysis, the Needham and Kring approach of assigning the "underlying", "undated" and "excess" mare lavas to a single age (the age of the oldest flow) (Fig. S4), and the reservations outlined above concerning 
the use of the "maximum" basin depth from Williams and Zuber (1998) as an "average depth" for the mare fill, appear to create unrealistically large volumes focused at single time intervals (3.5 Ga for Imbrium and 3.8 for Serenitatis), that tend to produce and significantly overestimate the peak flux at these times (their Figure 2b; Fig. S1b here). In a final step, the resulting production functions were then plotted (their Figure 2b; Fig. S1b here) and were summarized in their Table S3. Needham and Kring conclude that these data clearly show that peak volatile releases occurred at $3.8 \mathrm{Ga}$ and $3.5 \mathrm{Ga}$.

Among the uncertainties in this approach, in addition to the total volumes and age assumptions for individual basins discussed above, are:

1) Eruption time period (duration): Volcanic unit ages, volumes, and gas release masses are binned in $100 \mathrm{Ma}$ intervals (N\&K, their Table S3). This binning effectively serves to reduce any individual eruptive peaks to an average of the $100 \mathrm{Ma}$ period. If the volumes of units and their individual ages were known with great accuracy, an individual peak could potentially greatly exceed the average, and its contribution to a lunar atmosphere could be underestimated.

2) Time-dependent volatile input during a single eruption: Gas release during volcanic eruptions is typically non-linear, decreasing as a function of time during the eruption. Depending on the eruption duration, this could have a significant effect on the volumetric contributions of volatiles to an atmosphere and its dissipation history. Similarly, individual gas species vent at different rates and times during eruptions, important considerations in potential buildup and retention in an atmosphere. We treat these factors in more detail in the main contribution.

3) Eruption repose period (time between eruptions): Similarly, summing the entire volume and flux for a 100 Ma period implies that this input was continuous into the atmosphere for a 100 Ma period. If the repose period was significant, the atmospheric contribution from a single event may completely dissipate, rather than contribute to the buildup from a longer term average input. The $\tau_{\mathrm{d}}$ values in our Table $1 \mathrm{~b}$ in the main text show that (ignoring the one-off Cobra Head event), two eruptions would have to occur within $\sim 4000$ years of one another for there to be a significant effect on prolonging a temporary atmosphere. Approximating the 20,000 to 60,000 year typical interval by normal distribution with mean 40,000 and standard deviation 20,000, a 4000 year interval would have a probability of $\sim 3 \%$.

\section{S3.1 Opportunities and prospects for current and future improved estimates of mare basalt volatile contributions to an atmosphere}

Clearly, improved stratigraphic relationships of dated lava flows in the most volumetrically significant lunar basins (e.g., Imbrium, Serenitatis) would be essential to decreasing the uncertainty in the Needham and Kring (2017) estimates, as would more precise determinations of the absolute ages of individual lunar basins. Also critically important is the initial volatile content of mare basalt magmas generated at depth and their global variability, as well as volatile release (e.g., Rutherford et al., 2017) and loss processes as a function of individual eruptions (e.g., Wilson and Head, 2018). Information on volumes of individual eruptions, their duration, and the chronology of volatile speciation and loss would be essential for the reliable determination of loss rates and contributions to a candidate lunar atmosphere. 
413

414

415

416

417

418

419

420

421

422

423

424

425

426

427

428

429

430

431

432

433

434

435

436

437

438

439

440

441

442

443

444

445

446

447

448

449

450

451

452

453

454

455

456

457

458

459

460

461

462

463

464

465

466

467

468

\section{References:}

Baker, D. M. H., \& Head III, J. W. (2013). New morphometric measurements of craters and basins on Mercury and the Moon from MESSENGER and LRO altimetry and image data: An observational framework for evaluating models of peak-ring basin formation. Planetary and Space Science, 86, 91-116. https://doi.org/10.1016/j.pss.2013.07.003

Baker, D. M. H., \& Head III, J. W. (2015). Constraints on the depths of origin of peak rings on the Moon from Moon Mineralogy Mapper data. Icarus, 258, 164-180. https://doi.org/10.1016/j.icarus.2015.06.013

Baker, D. M. H., Head III, J. W., Neumann, G. A., Smith, D. E., \& Zuber, M. T. (2012). The transition from complex craters to multi-ringed basins on the Moon: Quantitative geometric properties from Lunar Reconnaissance Orbiter Lunar Orbiter Laser Altimeter (LOLA) data. J. Geophys. Res., 117, E00H16. https://doi.org/10.10.29/2011JE004021

Evans, A. J., Soderblom, J. M., Andrews-Hanna, J. C., Solomon, S. C., \& Zuber, M. T. (2016). Identification of buried lunar impact craters from GRAIL data and implications for the nearside maria. Geophys. Res. Lett., 43, 2445-2455. https://doi.org/10.1002/2015GL067394

Gong, S. X., Wieczorek, M. A., Nimmo, F., Kiefer, W. S., Head III, J. W., Huang, C. L., Smith, D. E., \& Zuber, M. T. (2016). Thicknesses of mare basalts on the Moon from gravity and topography. Journal of Geophysical Research, 121(5), 854-870. https://doi.org/10.1002/2016je005008

Head III, J. W. (1974). Orientale multi-ringed basin interior and implications for the petrogenesis of lunar highland samples. The Moon, 11, 327-356, 1974.

Head III, J. W. (1982). Lava flooding of ancient planetary crusts: Geometry, thickness, and volumes of flooded lunar impact basins. The Moon and the Planets, 26, 61-88.

Head, J. W., \& Lloyd, D. D. (1971). Near Terminator Photography. Apollo 14 Preliminary Science Report $S P-272,297-300$, NASA Special Publication.

Hiesinger, H., Head III, J. W., Wolf, U., Jaumann, R., \& Neukum, G. (2002). Lunar mare basalt flow units: Thicknesses determined from crater size-frequency distributions. Geophysical Research Letters, 29(8). https://doi.org/10.1029/2002GL014847

Hiesinger, H., Head III, J. W., Wolf, U., Jaumann, R., \& Neukum, G. (2011). Ages and stratigraphy of lunar mare basalts: A synthesis. In W. A. Ambrose and D. A. Williams (Eds.), Recent Advances and Current Research Issues in Lunar Stratigraphy (pp. 1-51). Geological Society of America Special Paper, 477. Boulder, CO: Geological Society of America. https://doi.org/ 10.1130/2011.2477(01)

Horz, F. (1978). How thick are lunar mare basalts? Proceedings $9^{\text {th }}$ Lunar and Planetary Science Conference, 3 (pp. 3311-3331). New York, NY: Pergamon Press, Inc.

Howard, K. A., Wilhelms, D. E., \& Scott, D. H. (1974). Lunar basin formation and highland stratigraphy. Reviews of Geophysics and Space Physics, 12, 309-327. https://doi.org/10.1029/RG012i003p00309

Johnson, B. C., Blair, D. M., Collins, G. S., Melosh, H. J., Freed, A. M., Taylor, G. J., et al. (2016). Formation of the Orientale lunar multiring basin., Science, 354, 441-444. https://doi.org/10.1126/science.aag0518

Lloyd, D., \& Head, J. W. (1972). Orientale basin deposits (Riccioli area) in Apollo 16 earthshine photography. In Apollo 16 Preliminary Science Report, NASA Spec. Pap., SP-315 (pp. 29-24-29-26). Washington, DC: National Aeronautics and Space Administration.

Needham, D. H., \& Kring, D. A. (2017). Lunar volcanism produced a transient atmosphere around the ancient Moon. Earth and Planetary Science Letters, 478, 175-178. 
https://doi.org/10.1016/j.eps1.2017.09.002

Neumann, G. A., Zuber, M. T., Wieczorek, M. A., Head, J. W., Baker, D. M. H., Solomon, S. C., et al. (2015). Lunar impact basins revealed by Gravity Recovery and Interior Laboratory measurements. Science Advances, 1, 1-10. https://doi.org/10.1126/sciadv.1500852

Robinson, M. S., Ashley, J. W., Boyd, A. K., Wagner, R. V., Speyerer, E. J., Hawke, B. R., et al. (2012). Confirmation of sublunarean voids and thin layering in mare deposits. Planet Space Sci, 69(1), 18-27. https://doi.org/10.1016/j.pss.2012.05.008

Rutherford, M. J., Head III, J. W., Saal, A. E., Hauri, E. H., \& Wilson, L. (2017). Model for the origin, ascent and eruption of lunar picritic magmas. American Mineralogist, 102, 2045-2053. https://doi.org/10.2138/am-2017-5994

Schaber, G. G. (1973). Lava flows in Mare Imbrium: Geologic evaluation from Apollo orbital photography. Proceedings of the $4^{\text {th }}$ Lunar Planetary Science Conference (73-92).

Schulze-Makuch, D., \& Crawford, I. A. (2018). Was there an early habitability window for Earth's Moon?, Astrobiology, 18(8), 985-988. https://doi.org/10.1089/ast.2018.1844

Smith, D. E., Zuber, M. T., Neumann, G. A., Lemoine, F. G., Mazarico, E., Torrence, M. H., et al. (2010). Initial observations from the Lunar Orbiter Laser Altimeter (LOLA). Geophysical Research Letters, 37, L18204. https://doi.org/10.1029/2010GL043751

Solomon, S. C., \& Head III, J. W. (1979), Vertical movement in mare basins: Relation to mare emplacement, basin tectonics and lunar thermal history. Journal of Geophysical Research, 84(B4), 16671682.

Solomon, S. C., \& Head III, J. W. (1980). Lunar mascon basins: Lava filling, tectonics and evolution of the lithosphere. Reviews of Geophysics and Space Physics, 18(1), 107-141.

Spudis, P. D. (1993). The Geology of Multiring Impact Basins: The Moon and Other Planets, Cambridge University Press: Cambridge, England.

Spudis, P. D., Wilhelms, D. E., \& Robinson, M. S. (2011) The Sculptured Hills of the Taurus Highlands: implication for the relative age of Serenitatis, basin chronologies and the cratering history of the Moon. Journal of Geophysical Research, 116, E00H03, https://doi.org/10.1029/2011JE003903

Stöffler, D., Ryder, G., Ivanov, B. A., Artemieva, N. A., Cintala, M. J., \& Grieve, R. A. F. (2006). Cratering history and lunar chronology. Reviews in Mineralogy and Geochemistry, 60, 519-596. https://doi.org/10.2138/rmg.2006.60.05

Thomson, B. J., Grosfils, E. B., Bussey, D. B. J., \& Spudis, P. D. (2009). A new technique for estimating the thickness of mare basalts in Imbrium Basin. Geophysical Research Letters, 36(12), L12201, https://doi.org/10.1029/2009g1037600

Weider, S. Z., Crawford, I. A., \& Joy, K. H. (2010). Individual lava flow thicknesses in Oceanus Procellarum and Mare Serenitatis determined from Clementine multispectral data. Icarus, 209(2), 323-336. https://doi.org/10.1016/j.icarus.2010.05.010

Whitten, J., Head III, J. W., Staid, M. I., Pieters, C. M., Mustard, J. F., Clark, R., et al. (2011). Lunar mare deposits associated with the Orientale impact basin: New insights into mineralogy, history, mode of emplacement, and relation to Orientale Basin evolution from Moon Mineralogy Mapper (M3) data from Chandrayaan-1. Journal of Geophysical Research, 116. https://doi.org/10.1029/2010JE003736

Whitten, J. L., \& Head III, J. W. (2013). Detecting volcanic resurfacing of heavily cratered terrain: 
525 Flooding simulations on the Moon using Lunar Orbiter Laser Altimeter (LOLA) data. Planetary and Space 526 Science, 85, 24-37. https://doi.org/10.1016/j.pss.2013.05.013

528 Williams, K. K., \& Zuber, M. T. (1998). Measurement and analysis of lunar basin depths from Clementine

Wilson, L., \& Head III, J. W. (2018). Controls on lunar basaltic volcanic eruption structure and morphology: Gas release patterns in sequential eruption phases. Geophysical Research Letters, 45, 58525859. https://doi.org/10.1029/2018GL078327

Yingst, R. A., \& Head III, J. W. (1997). Volumes of lunar lava ponds in South Pole-Aitken and Orientale Basins: Implications for eruption conditions, transport mechanisms and magma source regions. Journal of Geophysical Research, 102(E5), 10,909-10,931.

Zuber, M. T., Smith, D. E., Watkins, M. M., Asmar, S. W., Konopliv, A. S., Lemoine, F. G., et al. (2013). Gravity field of the Moon from the Gravity Recovery and Interior Laboratory (GRAIL) Mission. Science, 339(6120), 668-671. https://doi.org/10.1126/science.1231507

Zuber, M. T., Smith, D. E., Neumann, G. A., Goossens, S., Andrews-Hanna, J. C., Head, J. W., et al. (2016). Gravity field of the Orientale basin from the Gravity Recovery and Interior Laboratory Mission. Science, 354, 438-441. https://doi.org/10.1126/science.aag0519 
549 Figures:
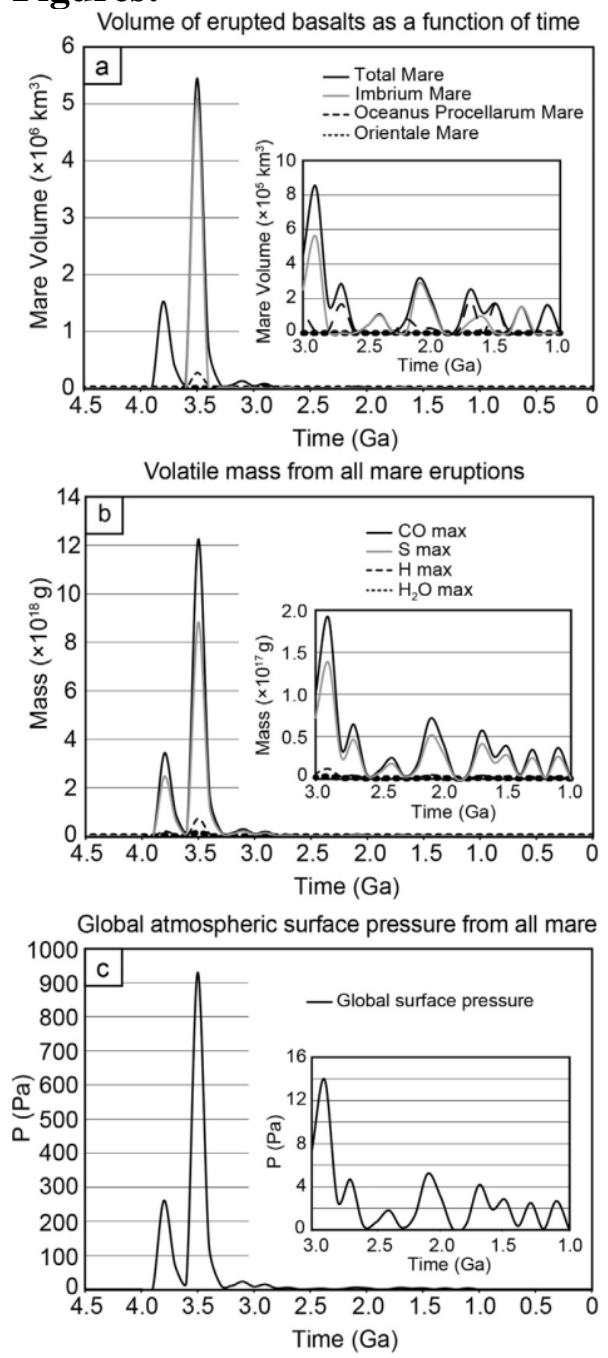

Figure S1. Volumes of erupted basalts and volatiles and lunar atmospheric pressure as a 552 function of time (from Needham and Kring, 2017). (a) Volume of erupted basalts as a 553 function of time, indicating peak volcanic activity primarily in Imbrium basin ca. $3.5 \mathrm{Ga}$; 554 the inset in each graph shows results for the time period from $3.0 \mathrm{Ga}$ to $1.0 \mathrm{Ga}$ at an 555 expanded scale. (b) Mass of volatiles, primarily CO and S, degassed during mare 556 emplacement. (c) Atmospheric surface pressure resulting from the volatiles released 557 during mare emplacement, with a peak pressure $\sim 1 \%$ of Earth's current atmospheric 558 pressure, corresponding to peak volcanic activity 3.5 Ga. Quantified results for panel (a) 559 are included in Table S2, and for panels (b) and (c) in Table S3 of Needham and Kring 560 (2017). 
Total mare basalt volume (\%)

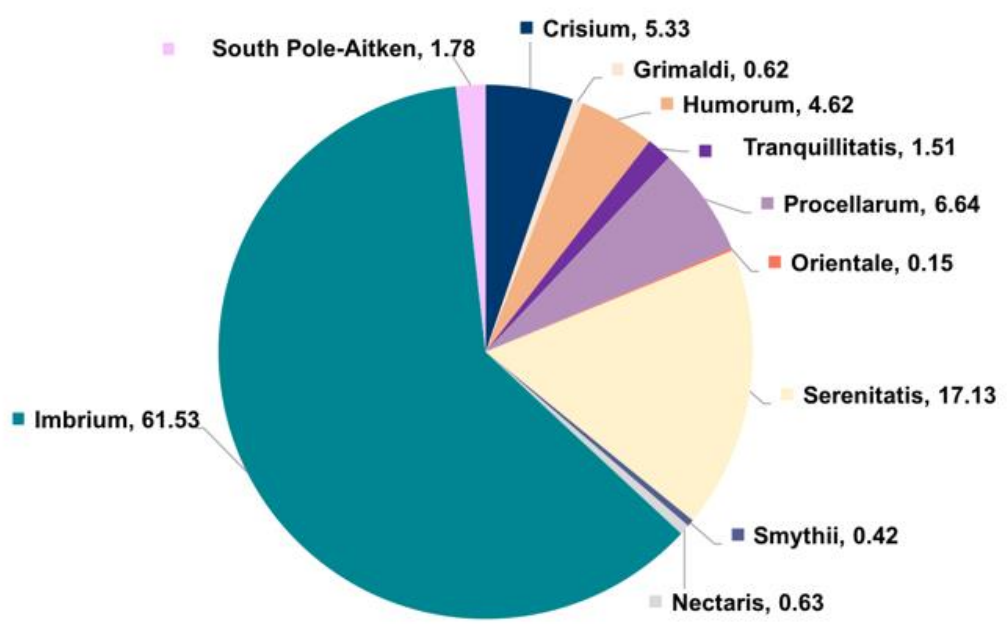

563 a) Total mare basalt fill for the 11 basins considered in Table 1 of Needham and Kring 564 (2017).

Percentage of total mare basalt volume in 11 major basins and 14 other basins used in the total mare basalt fill calculation of Needham and Kring (2017)

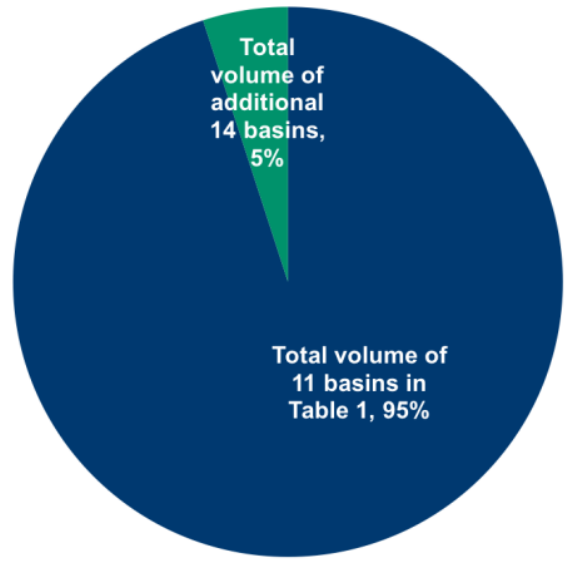

566 b) Percentage of total mare basalt volume in 11 major basins and 14 other basins used in. the total mare basalt fill calculation of Needham and Kring (2017). 


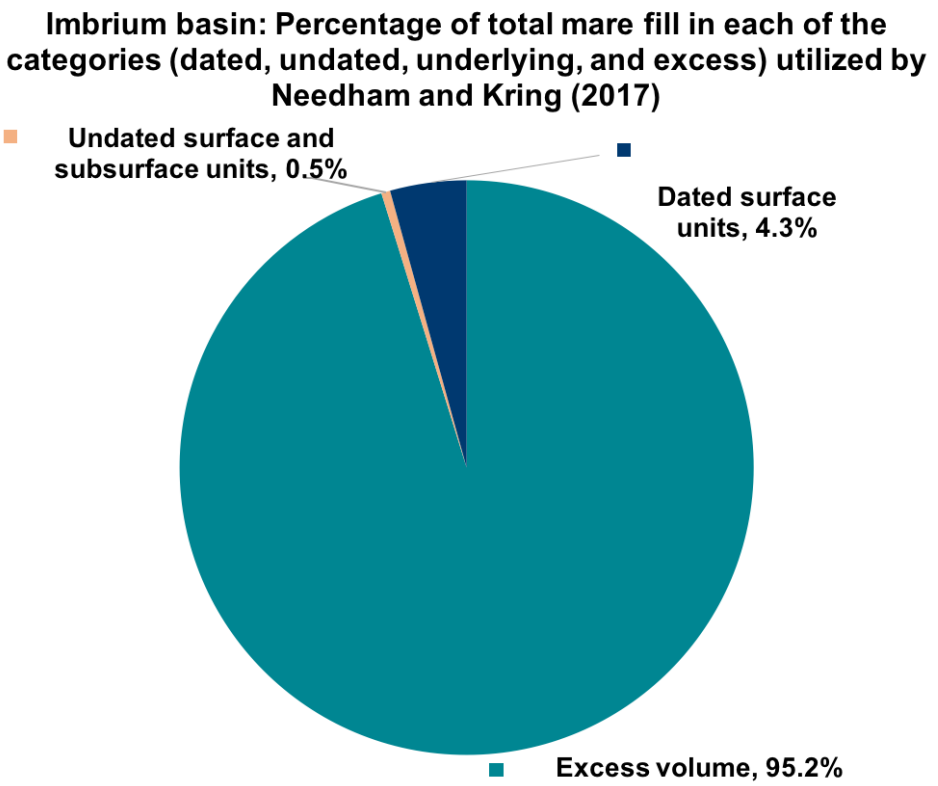

570 c) Imbrium basin: Percentage of total mare fill in each of the categories (dated, undated, underlying, and excess) utilized by Needham and Kring (2017).

Serenitatis Basin: Percentage of total mare fill in each of the categories (dated, undated, subsurface, and excess) utilized by Needham and Kring (2017)

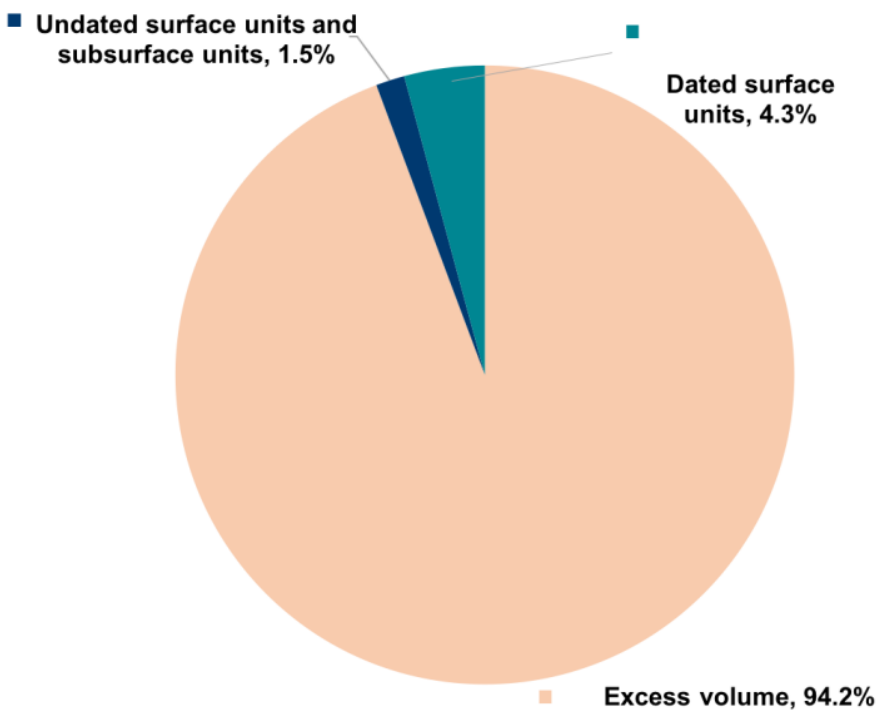

574 d) Serenitatis Basin: Percentage of total mare fill in each of the categories (dated, 575 undated, underlying, and excess) utilized by Needham and Kring (2017). See Figure S3 for explanation of Needham and Kring (2017) unit age assignments.

Figure S2. Relative percentages of mare fill. 


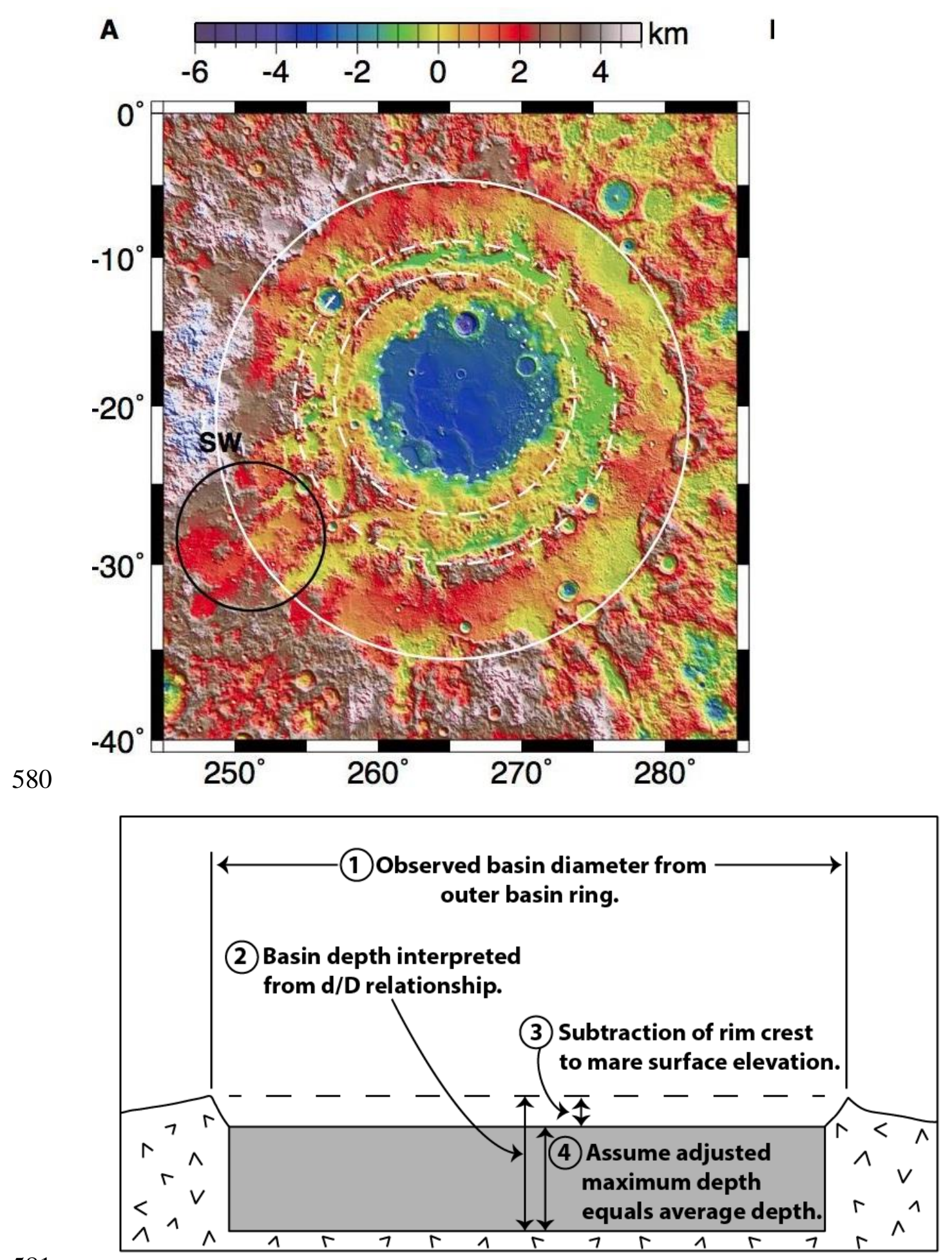

Figure S3. Topography of a typical multi-ring basin geometry and mare fill: a) Orientale basin topographic map showing that the deepest part of the basin (blue) is not equivalent to the average depth. b) Assumption that the maximum basin lava fill thickness is 


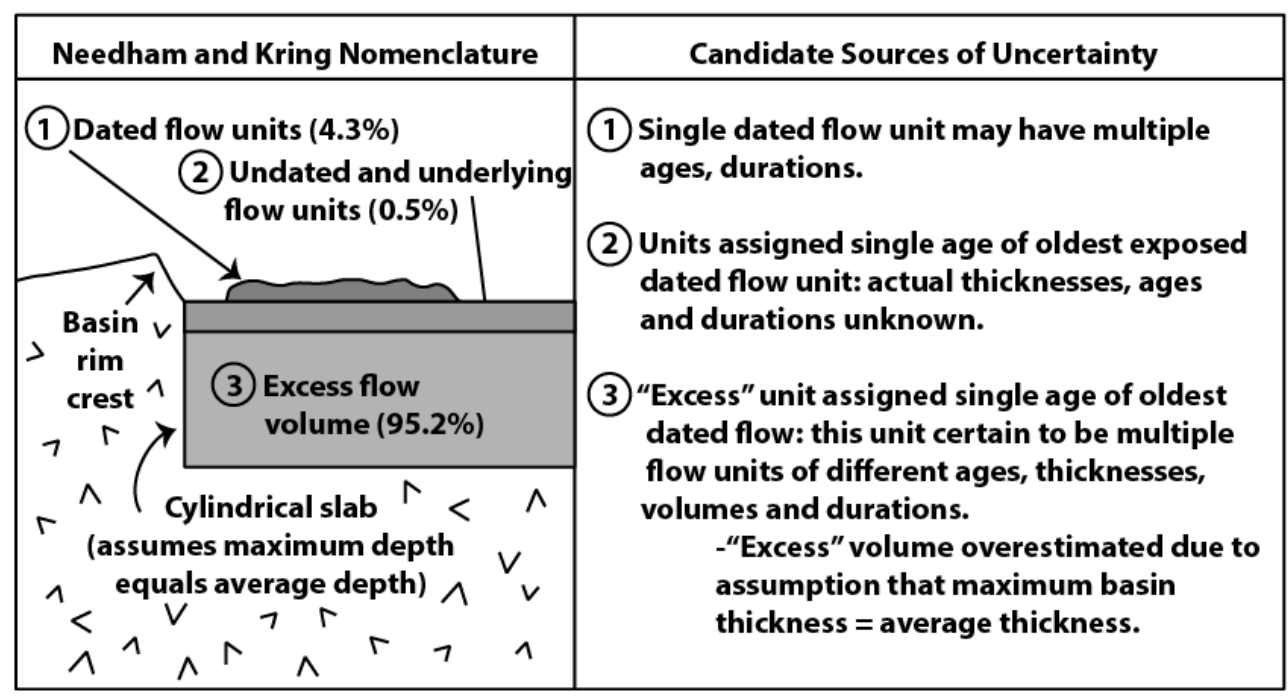

589 Figure S4. Cross-section of a multi-ring basin lava fill illustrating assignments of

590 different types of dated units by Needham and Kring (2017) and candidate sources of 591 uncertainty in estimating basin lava fill thicknesses and volumes. Numbers in

592 parentheses show the percentages of each type of unit assigned by Needham and Kring 593 (2017) to age distributions in the Imbrium basin. 